\title{
Discussion Paper No. 16-026 \\ Renewable Energy Targets in the Context of the EU ETS: Whom do They Benefit Exactly?
}

Florian Landis and Peter Heindl

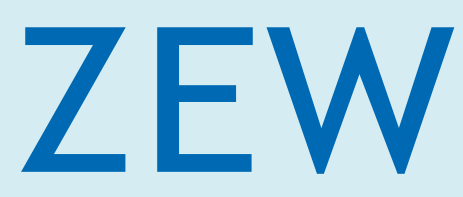

Zentrum für Europäische Wirtschaftsforschung $\mathrm{GmbH}$ Centre for European Economic Research 


\section{Discussion Paper No. 16-026 \\ Renewable Energy Targets in the Context of the EU ETS: Whom do They Benefit Exactly?}

Florian Landis and Peter Heindl

Download this ZEW Discussion Paper from our ftp server:

http://ftp.zew.de/pub/zew-docs/dp/dp16026.pdf

Die Discussion Papers dienen einer möglichst schnellen Verbreitung von neueren Forschungsarbeiten des ZEW. Die Beiträge liegen in alleiniger Verantwortung der Autoren und stellen nicht notwendigerweise die Meinung des ZEW dar.

Discussion Papers are intended to make results of ZEW research promptly available to other economists in order to encourage discussion and suggestions for revisions. The authors are solely responsible for the contents which do not necessarily represent the opinion of the ZEW. 


\title{
Renewable Energy Targets in the Context of the EU ETS: Whom do They Benefit Exactly?
}

\author{
Florian Landis*, Peter Heindl ${ }^{\dagger}$
}

March 2016

\begin{abstract}
We study how European climate and energy policy targets affect different member states and households of different income quintiles within the member states. We find that renewable energy targets in power generation, by reducing EU ETS permit prices, may make net permit exporters worse off and net permit importers better off. This effect appears to dominate the efficiency cost of increasing the share of energy provided by renewable energy sources in the countries that adopt such targets. While an increase in prices for energy commodities, which is entailed by the policies in question, affects households in low income quintiles the most, recycling revenues from climate policy allows governments to compensate them for the losses. If renewable targets reduce the revenues from ETS permit auctions, member states with large allocations of auctionable permits will lose some of the ability to do so.
\end{abstract}

Keywords: Distributional effects; EU climate policy; renewable energy target JEL-Classification: H23; Q52; Q54

${ }^{*}$ Landis (corresponding author): ETH Zürich, Dep. of Management, Technology and Economics, Centre for Energy Policy and Economics, Zürichbergstrasse 18, 8092 Zürich, Switzerland, E-mail:landisf@ethz.ch. This research received funding from the European Community's Seventh Framework Programme under Grant Agreement No. 308481. We thank Denny Ellerman, Sebastian Rausch, and Oliver Schenker for useful comments.

${ }^{\dagger}$ Heindl: Centre for European Economic Research (ZEW), L7 1, 68161 Mannheim, Germany. E-mail: heindl@zew.de. This research received funding from the German Ministry of Education and Research under Grant Agreement No. 01UN1204A, 'Sozialpolitische Konsequenzen der Energiewende in Deutschland.' 


\section{Introduction}

The climate policy of the European Union (EU) has distributional consequences across households, industries, and countries. In order for the EU to be able to continue to pursue ambitious targets in climate policy, policy implementation needs to keep these distributional consequences in check: In order to facilitate unanimous agreement on targets, it must be avoided that some, especially less affluent, member states bear disproportionately big shares of the overall policy cost. And in order for countries to implement policies to meet their targets on the national level, political opposition caused by an uneven distribution of the costs within the countries should be avoided. Unevenly distributed impacts have to be expected as low-income households usually spend a larger share of their income on energy services when compared to wealthier households.

The EU's policy design shows recognition of this problem by allocating auction revenues from the European Emission Trading System (EU ETS) to member states base on their economic abilities. The EU's rules further encourage member states to use their allocated permit auction revenue for counteracting unintended distributional impacts of climate policies (among other recommended uses of the revenue).

This paper analyses the effectiveness of the EU's distribution of permit auction revenues in addressing existing distributional issues and analyses the interaction of EU targets for renewable power generation with this redistribution mechanism. We examine the costs and distributive effects of the EU's 20 percent emission reduction target for the year 2020 across and within EU member states. We apply the computable general equilibrium (CGE) model PACE in order to examine costs and distributional effects across and within EU member states under different policy scenarios. In order to allow an assessment of effects within member states, the model disaggregates consumers into five representative households (income quintiles) in each member state.

We examine the costs of the existing EU ETS with and without additional mandatory targets for renewable energy sources (RES) in the power sector at the national level. In addition, we examine the distributive effects of an EU-wide carbon tax targeting the sectors which are not yet covered by the EU ETS. Since the resulting costs at the household level and across the income distribution are contingent on the mode of revenue recycling (the way tax and ETS revenues are being returned to the economy by the member states), we compare partial and full revenue recycling via the existing tax and transfer schemes of the member states to a situation without revenue recycling. In the latter case, all revenues are invested in projects which yield a return in the far future, for instance non-market based climate mitigation projects.

There is a large body of literature on the distributional effects of climate policy. Most studies analysing expenditure patterns suggest that direct car- 
bon taxation will cause regressive effects if the prices of necessities, such as electricity or space heating, are affected. In contrast, direct taxation of the carbon content of transport fuels tends to be neutral or even progressive (Sterner, 2012). But restricting the analysis to expenditure patterns ignores important effects on the income side. Boccanfuso et al. (2011) emphasises the importance of general equilibrium effects on the distributional effects of climate policy in developing countries. If climate policy causes important changes for factor income (land rents, capital income, labour income), according to this argument, CGE models are a valuable tool for keeping track of these effects. Rausch et al. (2011) provide a CGE analysis of a hypothetical cap-and-trade scheme in the United States, assuming a carbon price of approximately USD 20 per ton of $\mathrm{CO}_{2}$ equivalent. Rausch et al. find a moderate and rather neutral incidence of the policy across the income distribution after revenue recycling. In particular, they conclude that "[...] progressivity on the sources [income] side is sufficiently strong to offset regressivity on the uses [expenditure] side so that carbon pricing is proportional" [p. 31]. This confirms the importance of general equilibrium effects on income for analysing distributional effects of climate policy. CGE studies on the distributional effects of climate policy in developing countries include O'Ryan et al. (2005, in Chile), Liang (2012, in China), Yusuf and Resosudarmo (2008, in Indonesia), Gonzalez (2012, in Mexico), Corong (2008, in the Philippines), and Alton et al. (2012, in South Africa). Most studies find that regressive effects of climate policy have to be expected but can be mitigated by means of revenue recycling (for instance lump-sum transfers).

Distributional effects of renewable energy standards in the United States are examined in a CGE model by Rausch and Mowers (2014). They find that a renewable energy standard would be about four times more costly than a 'comprehensive market-based carbon pricing policy' [p. 582]. A renewable energy standard would further cause regressive distributional effects [p. 574]. Since the policy does not raise revenues, options for mitigating distributional effects through revenue recycling do not exist. Buddelmeyer et al. (2012) combine a CGE model with a microsimulation model to assess the impact of carbon emission reductions by cap-and-trade in Australia. The authors find a moderately progressive distribution of costs after revenue recycling by lump-sum transfers. However, progressivity diminishes over the course of time as recycled permit revenues eventually become too small to compensate households in the second income quintile. We are not aware of a CGE study that analyses the distributional effect of European climate policy across member states and we seem to be the first to analyse interactions between the distribution of EU ETS permit auction revenue and ancillary EU climate policy targets.

We find that, in the absence of revenue recycling, observed distributional effects show regressive patterns within most EU member states. If revenues are fully or partly recycled in accordance to existing tax and trans- 
fer schemes, the resulting patterns of distribution are progressive. In some cases, the lowest income quintiles would even profit in absolute terms. Across member states, most Eastern members will profit from climate policy targets, whether in the case of a cap on emissions alone or given ancillary renewable energy targets. Ambitious targets for RES in national power generation can have two different effects on the distribution of climate policy cost. First, they increase the cost to countries that implement the RES targets and at the same time reduce the demand of the power sector for ETS permits thus decreasing the effort required from other countries to meet the ETS cap. Second, this reduction in permit demand lowers the permit price thus reducing the value of the shares of permit auction revenue allocated to different member states. We find the latter effect to dominate the former, if several net permit importing member states adopt ambitious RES targets. That is, a country will gain (lose) from the ancillary RES targets if it has a negative (positive) trade balance in the ETS permit market almost irrespective of whether the country itself is subject to a binding RES target or not.

The remainder of this paper is organised as follows. The model is presented in Section 2, including a data description, the procedure of disaggregation of households along the quintiles of the income distribution, and the policy scenarios. Results are discussed in Section 3. Section 4 concludes.

\section{Model}

Our study employs the PACE model and extends it by splitting the EU member states' representative households into income quintiles. This section gives an overview of the model, the data used for calibration, and the scenarios that were run. The model is described in more detail in Appendix A.

\subsection{The PACE model}

The PACE model is a GTAP-in-GAMS CGE model $^{1}$ with extensions that make it suitable for the analysis of climate and energy policies at a global scale. Besides the 28 member states of the EU, the model includes the world regions China, Japan, South Korea, Indonesia, India, Canada, USA, Mexico, Brazil, Russia, Austria and New Zealand, Rest of Annex I ${ }^{2}$, Rest of World. In each region, representative households own (region specific) production factors that are employed by the regional sectors for producing globally traded commodities. Regional governments collect tax revenues, demand government services, and make transfers to households. The introduction of

\footnotetext{
${ }^{1}$ See for example https://www.gtap.agecon.purdue.edu/about/data_models.asp

${ }^{2}$ That is Annex I to the United Nations Framework Convention on Climate Change (UNFCCC).
} 
five representative consumers per European member state is a crucial extension to the standard PACE model made by this paper. The five representative households represent income quintiles and both their expenditure and their income are calibrated by using survey data from European member states.

The production factors owned by the representative households are labour, capital, and resources (viz. the fossil fuels: crude oil, gas, and coal). The representative households in each region consume their specific consumption bundles and demand fixed amounts of the investment good. Labour and capital are mobile between sectors within countries. Technology specific capital for power generation is an exception to this and is in fixed supply. Governments in each region levy taxes, issue subsidies, make transfers to households, and demand fixed amounts of government services.

The factors owned by households are employed by industrial sectors to produce sector specific outputs which are traded between regions and used as intermediate inputs by other sectors and are also consumed by representative agents. PACE uses nested constant elasticity of substitution (CES) production functions to represent production in different economic sectors, trade, and final consumption. The standard production function (see also Fig. 5 in the Appendix) combines the use of intermediates with a value added-energy composite at the top level. The value added-energy composite combines a labour-capital nest with the energy composite. The latter again combines electricity input with a coal-non-coal aggregate which again is an aggregate of oil and gas consumption. In order to account for carbon taxation, all fossil fuel inputs to the energy composite are associated with the amount of $\mathrm{CO}_{2}$ emitted by the burning of the fuels. This production structure applies to all productive sectors (including production of non-traded commodities for investment, government consumption, and private consumption by households), except power generation and extraction of fossil fuels.

In the case of power generation, the model distinguishes the five generation technologies 'oil', 'gas', 'coal', 'renewable', and 'nuclear'. They all produce the homogeneous good electricity which is traded at a common market price. The production technologies differ in fuel and capital intensity, each technology using its specific fossil fuel and capital type. The technologies combine non-capital inputs in fixed proportions and trade them off with the technology specific capital stock. This trade-off happens at an elasticity of substitution that allows for calibration of price elasticity of electricity supply per technology (also see Fig. 6 in the Appendix). In the case of fossil fuel extraction, the fuel specific resource is used together with non-resource inputs in fixed proportions (extraction) and this composite can be traded off against more of the non-resource inputs (exploration) at a positive elasticity of substitution on the top level (see Fig. 7 in the Appendix).

Industry output produced in one region is thus either exported or sold on the domestic market alongside with the imported version of the good. Both 
are traded off against each other according to the Armington assumption (Armington, 1969), which results in a domestic market price index. The imported version of the good is again an aggregate of the varieties that are produced in other regions.

Taxes in PACE are levied on production factors and final products. Countries levy tariffs on imports and subsidise exports. Carbon taxes (for meeting emission targets outside the EU ETS) and emission allowance expenses (allowances are issued for sectors whose emissions are governed by the EU ETS) are both proportional to the amount of fossil fuels burned in the process of energy generation. $\mathrm{CO}_{2}$ emission rights are in both cases modelled as a commodity in fixed supply. Regarding emissions within the EU ETS, the market clearing price for such emission rights corresponds to the market price of ETS allowances. Outside the EU ETS, the modelled market price for emission rights corresponds to the $\mathrm{CO}_{2}$ tax that governments would have to impose on emitters in order to efficiently meet their national targets. The emission rights are owned by the national governments and revenues from selling them are given to households via lump-sum transfers or are invested, depending on the policy scenario. In scenarios where member states are assumed to employ cost-efficient but non-revenue raising policies for emissions reductions in non-ETS sectors, this policy is modelled as a carbon tax and the tax revenues from each sector and household are refunded through differentiated subsidies on sectoral output and household consumption.

Besides this standard PACE setup, additional mechanisms need to be included in the model for adequately representing EU climate policy and its distributional impacts for this study. First, some sectors governed by the ETS receive free emission allowances. While the option of selling the received permits at market prices induces firms to abate at efficient levels, the advantage of receiving free permits makes them more profitable, which induces market entry until market prices correct for this effect. This endogenous reduction is modelled by a subsidy on the industries output price that is financed by the value of carbon permits that the industry received for free.

Second, in some scenarios, a target for the share of power generation from RES in total electricity shall be reached by implementing a quota. To meet the quota, the power sector, representing the operators of different generation technologies, subsidises power from RES. Thus, its subsidised generation cost can compete with the generation cost of other technologies even at the required high deployment rates of RES. The additional costs of this internal subsidy are financed with a markup on total power sales, which is modelled as a sales tax.

Third, real government consumption is kept constant by the model by adjusting lump-sum transfers from the government to the households.

Fourth, in order to keep track of revenues from auctioning permits in the EU ETS, the model needs to distinguish between the amount of emis- 
sion allowances that are allocated to sectors for free and the amount that is auctioned. The revenue from auctioning permits is then distributed according to a fixed set of shares among the governments of the member states. In some scenarios, national governments are required to spend their revenue from permit auctioning on investments which increases the demand for commodities that are associated with investment.

\subsection{Data}

The data source for the calibration of PACE originates from the Global Trade Analysis Project (GTAP) (Aguiar et al., 2012). Version 8.1 of the GTAP data base provides the model with input output structures for production sectors as well as trade patterns.

In order to capture impacts of rising prices of energy commodities on consumers with different levels of affluence in different countries, we disaggregate the representative household of each country into five households that represent the income quintiles. We combine two sets of survey results to split expenditures on the one and income on the other hand between the quintiles. On the expenditure side, national expenditures for different consumption goods have to be split into the expenditure of different income quintiles. The resulting expenditures will be used to calibrate the nested CES functions representing the quintiles' consumption baskets. On the income side, factor endowments and government transfers have to be realistically distributed among quintiles in the benchmark. While endowments are fixed quantities in the model, transfers are endogenously determined in the scenarios. In these scenarios, changes from benchmark transfers will be distributed among the quintiles in proportion to the initial benchmark transfers.

\section{Expenditure of income quintiles}

The model imitates information from Eurostat on the amount of overall consumption and the share of the energy goods in overall consumption for each quintile. It is worthwhile to note that we rely on household expenditures in Purchasing Power Standard (PPS) provided by Eurostat in order to make consumption bundles comparable between member states when reporting results. The household budget surveys of EUROSTAT (2014) provide expenditures per household and per adult equivalent for five quintiles in all EU member states for the year 2010 .

National expenditure shares for energy goods in GTAP do not necessarily match expenditure shares found in the household surveys by Eurostat. We focus on energy commodities and use Eurostat survey results to distribute both total expenditures and expenditures for energy commodities realistically across quintiles. Total consumption expenditures of the representative household in GTAP are distributed among quintiles in proportion to per 
capita expenditures within the income quintiles defined by Eurostat household surveys. Similarly, expenditures on energy commodities according to GTAP are distributed among quintiles in proportion to per capita energy expenditures according to surveys. Expenditures for non-energy commodities are distributed in fixed (within member states) proportions among quintiles so that expenditures for energy and non-energy commodities add up to total expenditures.

\section{Income of quintiles in PACE}

On the income side, the PACE model distinguishes between wage earnings, rents on capital and resources, and net transfers from government to households which are not necessarily positive.

In order to split these revenue streams among income quintiles, the Household Finance and Consumption Survey (HFCS) by the European Central Bank (ECB) is consulted. The data are available for the following 15 members of the eurozone: Austria, Belgium, Cyprus, Germany, Spain, Finland, France, Greece, Italy, Luxembourg, Malta, Netherlands, Portugal, Slovenia, and Slovakia. We group these countries into Western, Eastern, and Southern Europe and assume that in the remaining EU member states, factor incomes are distributed across households according to the European area (viz. South, East, or West) that they belong to. Thus, of the member states not included in the HFCS , Bulgaria, Czech Republic, Estonia, Latvia, Lithuania, Hungary, Poland, and Romania are included in the Eastern European region. Croatia is part of Southern Europe. Denmark, Ireland, Sweden, and the United Kingdom are included in Western Europe.

Income classes of the HFCS are split into the broad fields wages, capital income, pensions, and transfers. The PACE model on the other hand, distinguishes labour income, rents from capital, income from resources, and transfers from the government to households or vice versa.

Transfers in GTAP and the HFCS do not seem to have congruent meanings (in the ECB surveys, transfers principally result in positive income, whereas they can also have a net negative impact on households' balance sheets in GTAP). The PACE benchmark calibration uses total (national) transfers regardless of their sign and distributes them among quintiles in proportion to the always positive transfer revenue indicated by the HFCS. Thus, if national governments transfer additional revenue from climate policies to households, transfers to quintiles in PACE change in proportion to benchmark transfers. The implemented calibration guarantees that the benefits from these additional transfers going to different quintiles are distributed in proportion to transfers in the ECB survey data.

From the remaining revenue flows of households in GTAP, labour income is identified with labour income in the HFCS survey, while capital and resource rents are identified with revenues from capital and pensions. This 
reflects the fact that capital rents in GTAP by far exceed pure capital income according to the HFCS and can be defended by acknowledging that pensions, at least to some extent, constitute rents on earlier investments.

Factor income from labour and capital by each household has to make up for household expenditures including savings and net transfers to the government. The national income from labour and capital according to GTAP is then distributed among quintiles such that the shares of labour and capital income in total factor income are 'as close as possible' to the numbers given in the HFCS survey (closeness was measured in terms of the 8-norm, which strongly reacts to the worst fit across households, regions, and factors; see Appendix A.4 for details).

\section{Sensitivity analysis with regard to pension revenues}

When calibrating income data from the ECB's HFCS to PACE, pension income in income surveys are associated with capital income according to GTAP. Thus, capital in the PACE model was distributed between income quintiles to match the distribution of capital and pension income according to the income survey. The consequence is that if climate policy affects capital revenue in the PACE model, this effect will be passed on to pensioners.

As an alternative interpretation of pension revenues in the income survey, we associate it with labour income in PACE. Thus, labour income as given by GTAP is distributed across income quintiles pursuant to how labour and pension income is distributed.

\section{Projecting the benchmark to 2020}

The benchmark social accounting matrixs (SAMs) given by GTAP reflect the global economy in 2004. In order to discuss future European climate and energy policy, the data are projected to 2020. For this purpose, national factor endowments are inflated according to regional growth projections from the European Commission's reference scenario (Capros et al., 2013). To reflect progress in energy efficiency, the energy consumption of production is also reduced by exogenous factors and in line with the aforementioned reference scenario. The various imbalances created by these changes are smoothed out by letting the model solve for equilibrium after factor endowment adjustments and after numerous intermediate changes to energy intensity. This procedure leads to the desired baseline 2020 projection.

Only at this stage, we distribute household income and expenditures among quintiles according to the above assumptions and according to data of 2010. While the distribution of national income levels across member states is updated according to EU projections about gross domestic product (GDP) growth, the distribution of income within member states is left at a 2010 level. We observe that changes between 2005 and 2010 in income 
distribution within member states are considerably more extensive than the distributional changes effected by the policy scenarios described in the following. The assumption that distribution of expenditures across income quintiles in 2020 will be the same as in 2010 is implausible, but we still believe that we are able to give reasonable estimates of how policy choices affect the distribution of policy cost across income groups within member states.

\subsection{Scenarios}

\section{No-policy scenario}

The 'no climate policy' (NoPolicy) scenario assumes the absence of climate policy. The model baseline is calibrated to the reference scenario by the European Commission (Capros et al., 2013), which assumes a binding EU ETS cap and a corresponding EU ETS allowance price. Therefore, the no-policy scenario represents a deviation from that baseline that is endogenously determined by the model by removing the cap. It can be argued that, similarly to the EU ETS sectors, non-ETS sectors in the Commission's reference scenario also are subject to policy intervention and would behave differently if such intervention was taken away. Our model is not able to take such policies into account which makes the policy environment for the non-ETS sectors in the NoPolicy scenario and the calibrated baseline identical. Only if emission targets are tightened beyond the reference scenario described by Capros et al. (2013), (price based) policies for emission reductions in non-ETS sectors are incorporated in the model.

\section{Emission target}

The 'cap for overall emissions' ( Cap) scenario assumes that the EU abides by their targets for 2020 and reduces overall emissions by 20 percent compared to 1990 levels. The emissions permitted under the target are distributed among EU ETS and non-ETS sectors according to the baseline given in Capros et al. (2013). The non-ETS emissions are then distributed among member states according to the same baseline. The EU ETS emissions are divided into those allowances which are freely allocated to sectors and those which are auctioned. Emission intensive sectors that are on the so-called leakage list in the PACE model receive all required allowances for free. Other sectors have to purchase an increasing share of allowances through auctions and will be purchasing all their allowances by 2027 . The initial share that is not purchased through auctions, will be received through free allocation as well.

The model endogenously keeps track of the allowances that remain for auctioning and distributes the revenues from the auctions across member 
states according to the rules set up in 2009/29/EC. ${ }^{3}$ The revenues from these auctions are assumed to be used by the member states to compensate households for parts of the policy cost. This is modelled by means of increasing the lump-sum transfers from the governments to the different household quintiles in proportion to the currently existing transfers according to ECB data.

The scenario Cap assumes that the targets for greenhouse gas emissions outside the EU ETS sectors are met by the member states through efficient (i.e, marginal cost of emission abatement is equalised across sectors and households as well as across fuel types), but non-revenue raising regulatory measures.

\section{Renewable target}

In the 'quota for renewable energy sources in power generation' (Cap+RES) scenario, member states are assumed to set themselves the same emission targets in and outside the EU ETS system as in the aforementioned scenario Cap. However, in addition to the emission target, several member states set themselves targets for the share of power they generate from RES. These member states are Belgium, Denmark, France, Germany, Luxembourg, the Netherlands, Sweden, and the UK. Each of them increases the share of RES in power generation to 10 percent above baseline levels (Table 1). The scenario Cap $+R E S$ assumes that these member states reach the target by mandating a renewable quota that the power sector has to finance by raising electricity prices. Thus, from the national governments' point of view, the renewable targets are revenue neutral.

Table 1: Renewable targets in 2020. The targets correspond to a 10 percent increase from the renewable share under 'current policies' (but are capped at 90 percent).

\begin{tabular}{lc}
\hline Country & Target [\%] \\
\hline Belgium & 28 \\
Denmark & 69 \\
France & 30 \\
Germany & 43 \\
Luxembourg & 43 \\
Netherlands & 35 \\
Sweden & 64 \\
UK & 45 \\
\hline
\end{tabular}

\footnotetext{
${ }^{3}$ http://ec.europa.eu/clima/policies/ets/cap/auctioning/docs/ia_ auctioning_final_en.pdf
} 


\section{Investment of ETS auctioning revenues}

The 'invest ETS auctioning revenues' (Invest) scenario again assumes the emission targets of Cap, but unlike the latter, does not recycle revenues from auctioning EU ETS allowances by transferring them to households. Instead the Invest scenario assumes a rigid implementation of Eu rules stating that revenues from these allowance auctions have to be used for investments in clean technologies. This increases the demand for investment goods but leaves less money to be allocated to consumption by the various households. In terms of current consumption, this policy scenario obviously reduces welfare. The benefits that such investments are supposed to have in the future are not captured by the PACE model.

\section{Renewable target with investment of ETS auctioning revenues}

The 'quota for renewable energy sources and invest ETS auctioning revenues' (Invest $+R E S$ ) scenario assumes the emission targets of Cap, the RES targets of $C a p+R E S$, and that the decision to invest EU ETS auctioning revenues are according to Invest. In terms of revenue to the government, the renewable target remains revenue neutral. The auctioning of EU ETS permits generates revenues that have to be invested in clean technologies, and the taxation of carbon has to meet emission targets outside the EU ETS which creates revenues that are recycled by handing out lump-sum transfers to the household quintiles.

\section{Taxation of household emissions with emission target}

Just as Cap, the 'tax emissions cap for overall emissions' (TaxCap) scenario includes national targets for non-ETS emissions, but assumes that they are reached by national carbon taxes. This generates additional revenue that may be recycled. The part of the carbon tax revenue that is levied on industrial fuel consumption is rebated to the industries in proportion to sales volumes and the part levied on households is returned to them on a lump-sum basis.

\section{Taxation of household emissions with emission target and renew- able target}

Just as $C a p+R E S$, the 'tax emissions quota for renewable energy sources in power generation' ( TaxCap+RES) scenario includes national targets for non-ETS emissions and shares for renewable power generation, but assumes that they are reached by national carbon taxes. The additional revenues are redistributed among industries and different households like in scenario 'tax emissions cap for overall emissions' (TaxCap). 


\section{Results}

\subsection{Distribution of costs across EU}

Results at the member state level refer to the aggregated change in the consumption budget of households within member states. Figure 1 depicts the percentage change in the consumption budget relative to the no-policy case. Detailed results for each member state are comprised in Tables 8-13 (column "overall", scenario Cap and Cap+RES) of Appendix B. A decrease of consumption in aggregate is expected until 2020 for most EU member states as a result of introducing the ETS cap (scenario Cap). However, the decrease in the consumption budget is moderate in most member states. Examples are France $(-0.09 \%)$, the United Kingdom $(-0.09 \%)$, Germany $(-0.13 \%)$, Spain $(-0.2 \%)$, and Italy $(-0.41 \%)$. Countries with a more pronounced reduction in the consumption budget include Greece (-1.09\%), Denmark $(-0.66 \%)$, the Netherlands $(-0.57 \%)$, and Poland $(-0.54 \%)$. Many Eastern member states are expected to benefit from EU climate policy. One reason for this is the relatively generous allocation of EU allowances to Eastern member states. Gains from the introduction of the ETs cap are most pronounced in Bulgaria $(+0.99 \%)$, Romania $(+0.97 \%)$, and Slovakia $(0.84 \%)$. The Czech Republic $(+0.49 \%)$ and Hungary $(+0.15 \%)$ are also expected to benefit. This result illustrates that many Eastern member states are actually over-compensated as a result of the EU-wide allocation of emission allowances.

If the ETS cap is augmented by a renewable energy target (scenario $C a p+R E S)$, moderate changes in consumption budgets occur under the provision of a cost-efficient implementation of the RES quota. The observed changes in the consumption budget are small for most of the member states and originate from changes in the ETS allowance price as well as from changes in associated costs and benefits from allowance trading. A positive effect of the RES quota is expected for Poland and Italy where total costs decrease under RES when compared to scenario Cap. Stronger negative effects caused by the introduction of the RES quota in addition to the ETS cap are observed for Bulgaria and Romania. Slovakia, the Czech Republic, and Hungary are also affected. For these countries, benefits under the additional RES quota are lower than in the situation without the RES quota. As the only non-Eastern member state, Denmark is expected to face a larger loss in the presence of the RES target $(-1.02 \%)$ when compared to the ETS only scenario $(-0.66 \%)$. Other Western EU member states, such as the United Kingdom, France, Belgium, Sweden, the Netherland, and Austria, also face larger costs under the additional RES target, but the changes in costs are not very pronounced. 
Distribution of relative impacts across member states in 2020

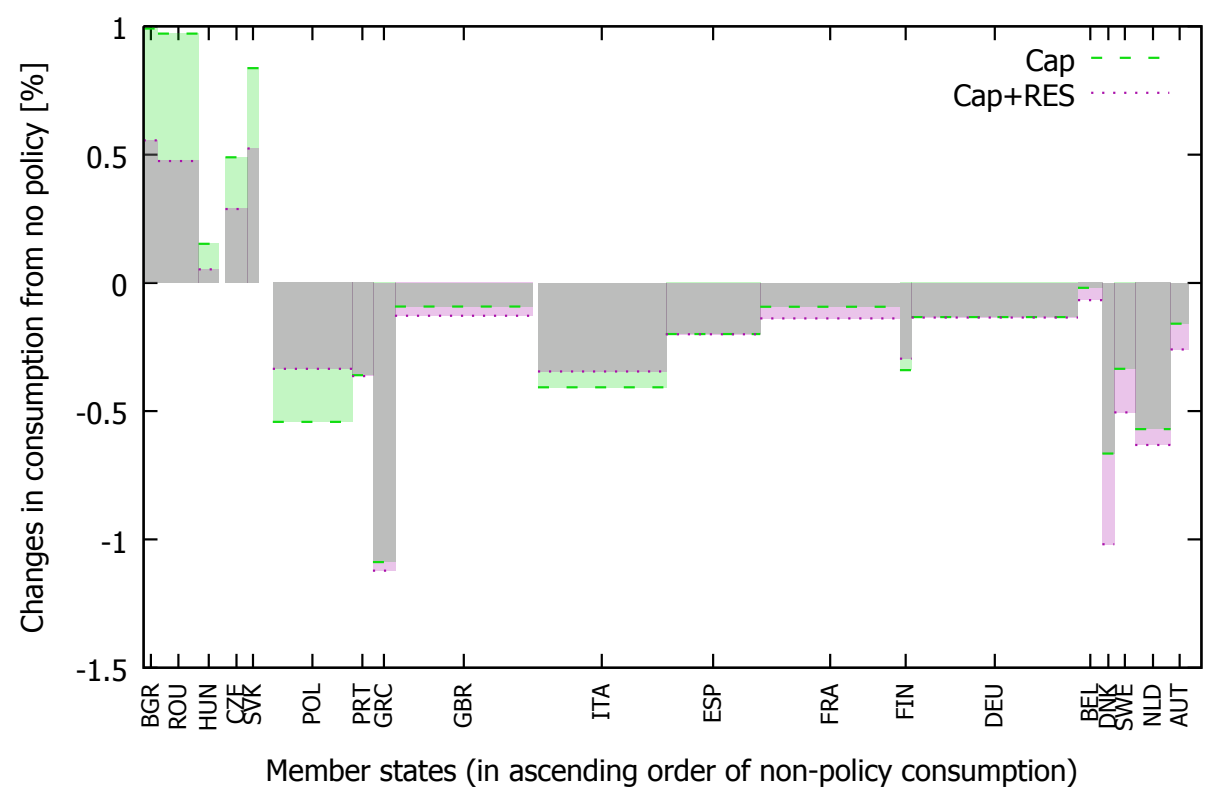

Figure 1: Relative policy cost by EU member state and scenario. Countries are sorted in ascending order of non-policy consumption based on Eurostat data. The width of the bars is proportional to the share of the population of each member state. 


\subsection{Distribution of costs within member states}

In order to assess distributive effects of EU climate policy within the member states, the household consumption in each of the states is disaggregated into five quintiles, according to the distribution of incomes, based on Eurostat data. The distribution of burdens at the household level within member states does not only depend on the overall expected costs, as depicted in Figure 1, but also on the recycling of revenues. In the following, we discuss the distributive impacts at the household level for three different assumptions about how much revenue is available for recycling: i) no recycling; ii) recycling of ETS-revenues; iii) recycling of ETS and carbon tax revenues.

\subsubsection{No revenue recycling}

Large costs of climate policy at the household level are to be expected in the absence of revenue recycling (scenarios Invest and Invest+RES). The situation is modelled in such way that all revenues are invested. While the costs of these investments are incurred in the present, their benefits occur in the future and thus, climate policy revenues do not benefit current private consumption. While this scenario is not necessarily realistic, it allows an examination of distributive patterns of climate policy under increased costs but unchanged income and transfers to private households and may serve as a reference for the comparison of alternative revenue recycling schemes. Figure 2 depicts the results. All results are reported in Tables 8-13 (columns "q1" to "q5", scenario Invest and Invest $+R E S)$ of Appendix B.

The distribution of costs differs between countries but also between the quintiles of the income distribution. Overall, there is the trend of a regressive incidence of climate policy in this scenario. There are large burdens in the top income quintile relative to other quintiles of the income distribution in some member states, i.e. in Bulgaria, Romania, the Czech Republic, and Poland. The observed inverted U-shaped pattern of incidence in these member states indicates that the top income quintile accounts for the largest burdens, but at least in the case of Bulgaria, the Czech Republic, and Poland, households in the lowest income quintile will also face considerable burdens. In most of the other member states, the largest burdens fall on the lowest income quintile in the absence of revenue recycling, so that we observe the trend of a regressive pattern of incidence in the scenario Invest. In this scenario, all member states and households, as represented by the quintiles of the income distribution, face a net loss of disposable income due to the investment of revenues in future projects.

In the scenario Invest $+R E S$, where revenues are invested in future projects while there is an additional RES target, we observe a change in the costs incurred by households. The additional RES target has pronounced effects in Bulgaria and Poland. In these countries, costs incurred by households 
Distribution of relative impacts across households in 2020

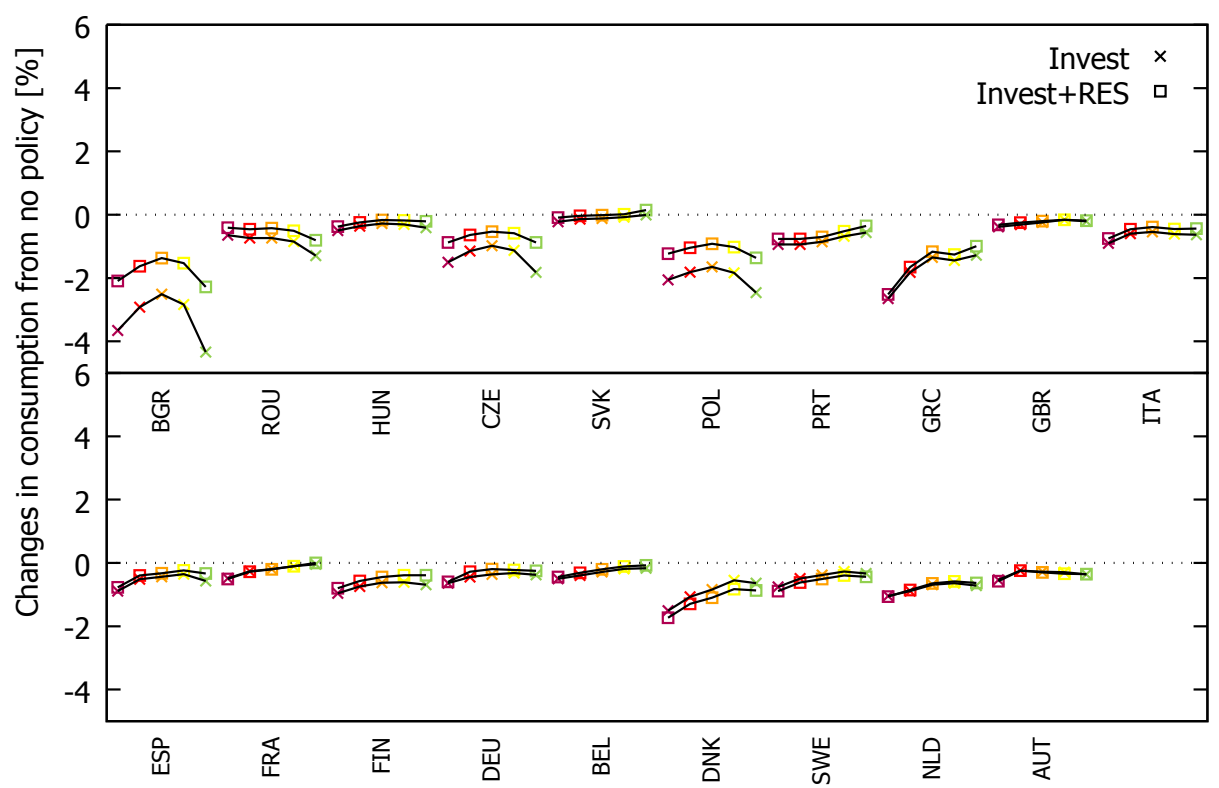

Figure 2: Policy costs by member states and quintiles of the income distribution in the absence of revenue recycling. Quintiles within member states are sorted according to their no-policy income with dark red representing the poorest quintile and green representing the richest.

under the additional RES target are considerably lower when compared to the scenario Invest. However, the general pattern of incidence remains unchanged. Slovakia is the only country which is expected to face net gains in the Invest $+R E S$ scenario. The upper two income deciles in Slovakia are expected to benefit from this policy, meaning that their consumption budget will increase.

\subsubsection{Recycling of ETS auction revenues}

In scenarios $C a p$ and $C a p+R E S$, we assume that member states recycle all revenues generated by the ETS via the pre-existing tax and transfer schemes. The model achieves this by recycling revenues in proportion to the existing transfer patterns, as give by the ECB's HFCS.

Figure 3 shows that the resulting distributive pattern differs strongly compared to the scenario without revenue recycling. Under revenue recycling, we find a pronouncedly progressive pattern of incidence for the majority of Eastern member states (i.e. Bulgaria, Romania, and the Czech Republic). Most of the households in Eastern member states would actually benefit from such a recycling scheme, meaning that they are over-compensated and 
Distribution of relative impacts across households in 2020

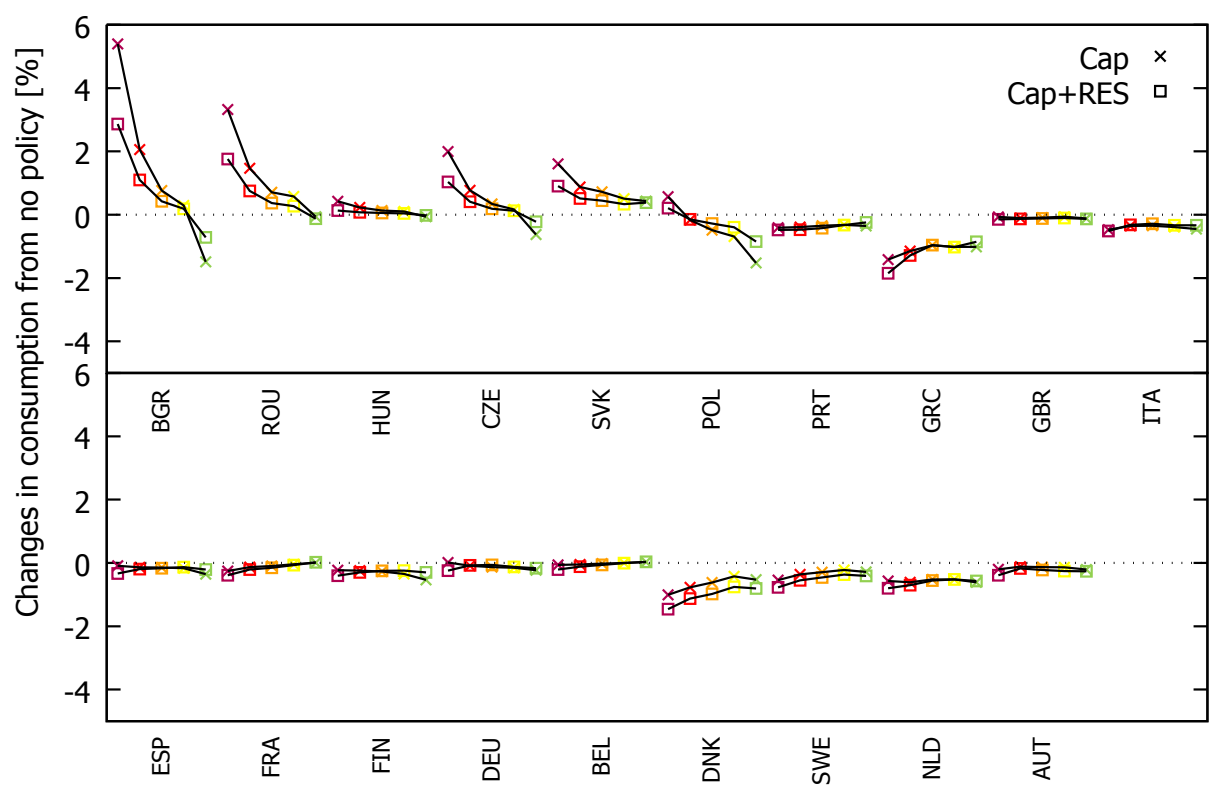

Figure 3: Policy costs by member states and quintiles of the income distribution with revenue recycling via existing transfer schemes.

face an increase in their consumption budget. Poland is the only Eastern member state in which the consumption budget of most of the households is expected to decrease.

For many Western member states, a rather neutral distribution of costs along the quintiles of the income distribution is observed after recycling of ETS revenues and costs are expected to be moderate. Exceptions are Greece, Denmark, and Sweden, for which a moderately regressive pattern is observed. Under revenue recycling, the total cost of climate policy can be even negative for some households in larger Western member states. Examples are Belgium and France in which the top income decile is expected to face negative costs. In Germany, the lowest income decile is expected to face negative costs from EU climate policy if EU ETS auction revenues are recycled.

The introduction of an RES target in addition to the ETS cap does not make much difference with respect to the occurring costs at the household level but costs tend to be larger in some Western member states. Examples are Greece, Spain, Germany, and the Netherlands, where the RES target will have negative consequences for low income households. The RES target further tends to increase overall burdens in Denmark and Sweden. In some Eastern member states, i.e. Bulgaria, Romania, the Czech Republic, and 
Slovakia, the RES target will decrease gains from EU climate policy, while the progressive pattern of incidence is preserved.

\subsubsection{Recycling of revenues from ETS auction and carbon taxes}

The EU ETS covers industrial installations across Europe, but several economic sectors are not covered by the system. In the previous scenario, it was assumed that non-ETs emissions are reduced in a cost-efficient manner by non-revenue raising policies of the member states. In this scenario, we investigate the case of hypothetical revenue-raising national carbon taxes in non-ETS sectors. It is assumed that both revenues from EU ETS auctions and carbon taxation of non-commercial emitters (i.e. private households) are recycled (scenarios TaxCap and TaxCap+RES). Carbon tax revenues generated in non-ETS industrial and commercial sectors are not redistributed to households. Results are depicted in Figure 4 and are reported in detail in Tables 8-13 of Appendix B.

The alternative tax and recycling regime leaves the progressive distributive pattern in Eastern member states mostly unchanged, while costs at the household level are further decreased (or benefits increased) when compared to the scenario Cap. Notable changes are observed for the majority of Western member states where the observed distributive pattern becomes more progressive. The distribution of burdens is now strongly progressive in Greece, where the lowest incomes are expected to benefit from climate policy. As opposed to the scenario Cap, a progressive pattern of incidence is also observed for countries such as Denmark, Sweden, and the Netherlands now. In many Western member states, households in the lowest income decile are even over-compensated as a result of revenue recycling in this scenario. In the present case, the lowest income quintile of Greece, the United Kingdom, Spain, France, Finland, Germany, Belgium, and Austria will benefit. The introduction of a RES target in addition to the ETS and the carbon tax again causes an increase of costs and a simultaneous decrease of benefits, while the overall progressive pattern remains unchanged.

The changes in distributional outcomes are attributable to changes in revenues that is recycled to households. The additional money that becomes available for this by using taxes to regulate household emissions is shown in Table 2 .

\subsection{Sensitivity Analysis}

When calibrating income data from the ECB's HFCS to PACE, pension income in the surveys is associated with capital income, according to the GTAP database. Thus, capital in the PACE model was distributed between the income quintiles to match the distribution of capital and pension income in the HFCS. The consequence is that if climate policy affects capital rev- 
Table 2: Revenue from ETS auction and carbon taxation in million EUR for scenario Cap with an emission cap and scenario Cap $+R E S$ with a cap and RES targets.

\begin{tabular}{|c|c|c|c|c|}
\hline & \multicolumn{2}{|r|}{ TaxCap } & \multicolumn{2}{|c|}{$T a x C a p+R E S$} \\
\hline & $\begin{array}{c}\text { tax } \\
\text { revenue }\end{array}$ & $\begin{array}{c}\text { ETS revenue } \\
\text { (permit price: } \\
22.05 \text { EUR/tCO2) }\end{array}$ & $\begin{array}{c}\text { tax } \\
\text { revenue }\end{array}$ & $\begin{array}{c}\text { ETS revenue } \\
\text { (permit price: } \\
12.19 \text { EUR/tCO2) }\end{array}$ \\
\hline AUT & 540.5 & 313.9 & 544.7 & 171.0 \\
\hline BEL & 855.3 & 572.4 & 891.5 & 311.8 \\
\hline BGR & 53.9 & 683.1 & 53.9 & 372.1 \\
\hline $\mathrm{HRV}$ & 213.4 & 108.9 & 213.2 & 59.3 \\
\hline CYP & 121.7 & 60.0 & 122.8 & 32.7 \\
\hline $\mathrm{CZE}$ & 129.5 & 1054.7 & 124.5 & 574.5 \\
\hline DNK & 484.7 & 281.6 & 489.5 & 153.4 \\
\hline EST & 17.1 & 205.4 & 16.6 & 111.9 \\
\hline FIN & 302.2 & 376.2 & 303.5 & 204.9 \\
\hline FRA & 3113.3 & 1234.7 & 3141.7 & 672.6 \\
\hline $\mathrm{DEU}$ & 5331.0 & 4516.6 & 5641.1 & 2460.2 \\
\hline GRC & 3025.2 & 782.4 & 3085.5 & 426.2 \\
\hline HUN & 209.9 & 337.0 & 208.0 & 183.5 \\
\hline IRL & 374.9 & 212.3 & 382.1 & 115.7 \\
\hline ITA & 4491.4 & 2174.1 & 4583.6 & 1184.2 \\
\hline LVA & 45.8 & 46.2 & 46.3 & 25.1 \\
\hline LTU & 42.9 & 122.3 & 43.2 & 66.6 \\
\hline LUX & 170.7 & 39.2 & 170.3 & 21.4 \\
\hline MLT & 122.7 & 23.1 & 120.4 & 12.6 \\
\hline NLD & 1132.0 & 757.0 & 1203.5 & 412.3 \\
\hline POL & 469.3 & 2818.0 & 459.8 & 1535.0 \\
\hline PRT & 507.6 & 397.0 & 510.6 & 216.2 \\
\hline $\mathrm{ROU}$ & 317.4 & 1126.3 & 302.7 & 613.5 \\
\hline SVK & 62.5 & 346.2 & 61.0 & 188.6 \\
\hline SVN & 161.5 & 99.2 & 162.4 & 54.1 \\
\hline ESP & 2091.8 & 1947.9 & 2097.2 & 1061.0 \\
\hline SWE & 536.2 & 200.8 & 537.8 & 109.4 \\
\hline GBR & 2695.7 & 2354.1 & 2904.1 & 1282.3 \\
\hline
\end{tabular}




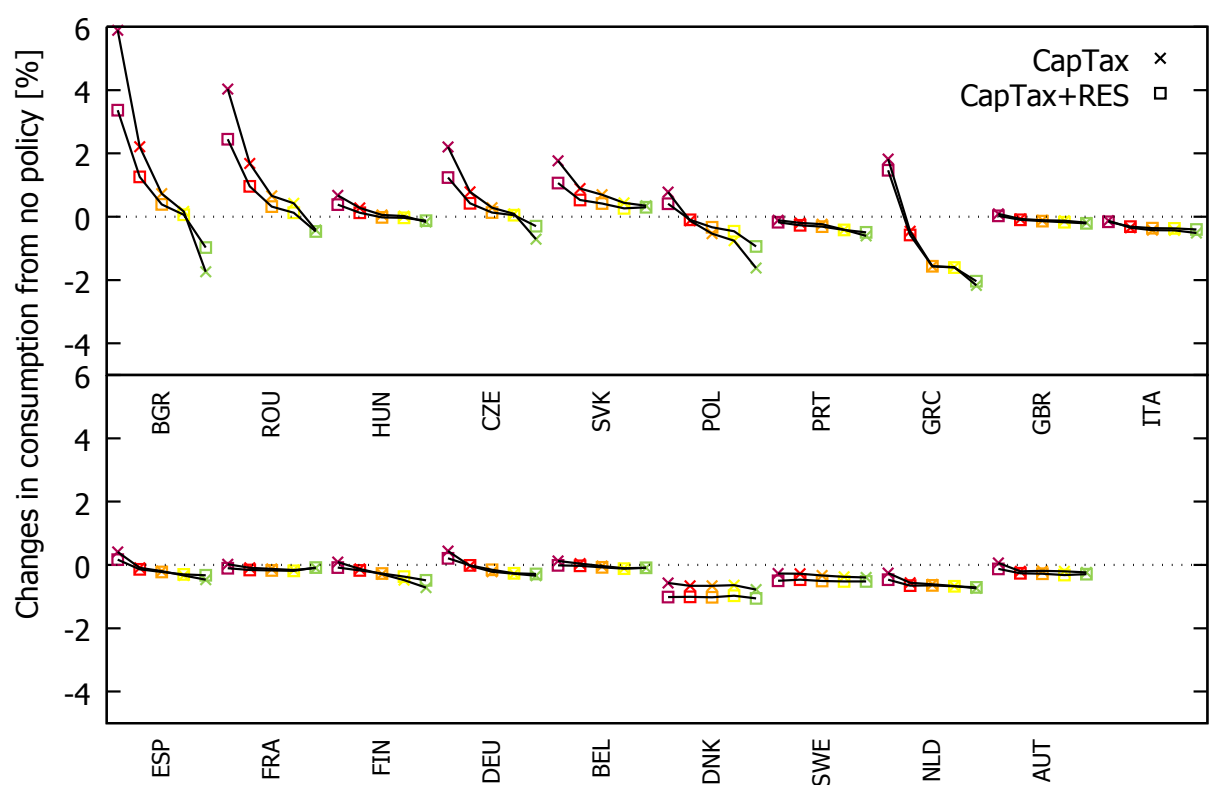

Figure 4: Policy cost by member states and quintiles of the income distribution if carbon emissions of households are taxed and revenues recycled via existing transfer schemes.

enues in the PACE model, this effect will be passed on to pensioners. As an alternative interpretation of pension revenues in the HFCS, we associate pensions with labour income in PACE. Thus, labour income as given by GTAP is distributed across income quintiles, pursuant to how labour and pension income is distributed.

Results of the sensitivity analysis are reported in line Cap-pl of Tables 8 13 of Appendix B. The results match the scenario Cap in which pensions were associated with capital income. The results show that there are minor differences between the two approaches. We observe small changes in disposable income which usually occur at the lower and upper end of the income distribution. The largest deviation is observed for Denmark. Costs are approximately 0.4 percentage points higher in the top income quintile under scenario Cap-pl than under scenario Cap. Deviations of up to 0.2 percentage points in the lowest quintile and -0.2 percentage points in the highest quintile are also observed for Bulgaria, Hungary, the Netherlands, and Poland. Thus, the assumption that pensions are equivalent to labour income tends to increase (decrease) costs in the lowest (highest) quintile of the income distribution, while the overall results and distributive patterns remain unchanged. 


\section{Conclusions}

In this paper, we examine the costs and distributive effects of EU climate policy across and within EU member states until 2020, based on a computable general equilibrium model with five representative households per member state representing income quintiles. We consider three policy options. First, the goal of reducing emissions by 20 percent until 2020 relative to 1990 levels may be approached by an emissions trading scheme (ETS) and complementary cost-efficient non-revenue raising policies at the member state level. Second, the same goal may be reached by the EU ETS and national carbon taxes on non-ETS emissions. Third, there exists the option of introducing ancillary renewable energy sources (RES) targets in addition to the aforementioned emission targets. Under all three options, the ETS generates revenue that is distributed among member states according to fixed shares and may be used to counteract undesired distributions of policy costs within member states.

Our results show that, at the member state level, many Eastern member states are expected to benefit from EU climate policy due to generous permit allocation. Poland is the only exception which is expected to suffer a reduction in the aggregated consumption budget of private households. The introduction of a RES target in addition to the EU ETS tends to decrease benefits in Eastern member states and tends to increase costs in Western member states. Exceptions are Poland, Italy, and Finland which are expected to incur lower aggregated costs, given the additional RES target.

In the absence of revenue recycling, we observe distributive patterns which tend to be regressive. This regressivity can be avoided in the majority of member states if ETS auction revenues are recycled via the existing tax and transfer schemes of the member states. If the EU ETS is not the only source of revenue generated by EU climate policy but is also augmented by national carbon taxes, regressive policy impacts can be avoided in all member states.

Our results provide several policy-relevant insights. First, the generous allocation of emissions allowances to Eastern member states reduces their policy cost and provides sufficient revenues to counteract regressive impacts on households in Eastern member states. Most Eastern member states may effectively be over-compensated and are expected to benefit from EU climate policy. The existing tax and transfer schemes in different member states provide a solid basis for counteracting regressive impacts of climate policy by means of revenue recycling. Only for few member states are ETS auction revenues and current transfer schemes insufficient for counteracting regressive impacts. These member states, if unable to find ways to optimise their transfers schemes, may implement revenue raising climate policies for reducing emissions outside the ETS and thus achieve non-regressive impacts across households. Second, the RES targets impact the distribution of costs 
between the member states since they cause the ETS allowance price to decrease. They weaken the distributive impact of allocating ETS permit auction revenue across member states. Even though member states with RES targets incur extra costs, they still reap overall benefits due to the permit price effects if they are net permit importers in the ETS permit market.

Our analysis provides a credible prediction of how effectively the distribution of ETS auction revenue can protect low income member states and households within them from excessive policy cost and reveals a hitherto undocumented interaction between RES targets and the effectiveness of this distribution of auction revenue. Yet, some limitations should be noted. First, lacking good data on income distribution in member states outside the eurozone, we make strong assumptions about how countries outside the eurozone can be compared with certain countries within the zone. Actual survey data from all EU member states may improve the reliability of analyses such as ours. Second, factors other than RES targets may reduce ETS permit prices. Generally speaking, if permit prices turn out to be unexpectedly low, but national emission targets remain expensive to achieve, member states may have to resort to revenue raising policies outside the EU ETS for financing recycling mechanisms that counteract regressive impacts within countries. And the effectiveness of distributing auction revenue among member states is always diminished at low permit prices.

\section{References}

Aguiar, A., McDougall, R., and Narayanan, B. (2012). Global trade, assistance, and production: The GTAP 8 data base.

Alton, T., Arndt, C., Davies, R., Hartley, F., Makrelov, K., Thurlow, J., and Ubogu, D. (2012). The economic implications of introducing carbon taxes in South Africa. WIDER Working Paper, 46.

Armington, P. S. (1969). A theory of demand for products distinguished by place of production. Staff Papers (International Monetary Fund), 16(1):159-178.

Boccanfuso, D., Estache, A., and Savard, L. (2011). The Intra-country Distributional Impact of Policies to Fight Climate Change: A Survey. Journal of Development Studies, 47(1):97-117.

Buddelmeyer, H., Hérault, N., Kalb, G., and van Zijll de Jong, M. (2012). Linking a Microsimulation Model to a Dynamic CGE Model: Climate Change Mitigation Policies and Income Distribution in Australia. International Journal of Microsimulation, 5(2):40-58.

Capros, P., De Vita, A., Tasios, N., Papadopoulos, D., Siskos, P., Apostolaki, E., Zampara, M., Paroussos, L., Fragiadakis, K., Kouvaritakis, N., 
Hoglund-Isaksson, L., Winiwarter, W., Purohit, P., Bottcher, H., Frank, S., Havlik, P., Gusti, M., and Witzke, H. P. (2013). EU Energy, Transport and GHG Emissions: Trends to 2050, Reference Scenario 2013. Publications Office of the European Union.

Corong, E. L. (2008). Tariff Reductions, Carbon Emissions, and Poverty: An Economy-wide Assessment of the Philippines. ASEAN Economic Bulletin, 25(1):20-31.

EUROSTAT (2014). Household budget surveys. Tables [hbs_exp_t133, hbs_exp_t211, hbs_str_t223, hbs_car_t311]; last accessed 2014-11-07.

Gonzalez, F. (2012). Distributional effects of carbon taxes: The case of Mexico. Energy Economics, 34(6):2102-2115.

Liang, C.-Y. (2012). Nonparametric structural estimation of labor supply in the presence of censoring. Journal of Public Economics, 96(1-2):89-103.

O'Ryan, R., de Miguel, C. J., Miller, S., and Munasinghe, M. (2005). Computable general equilibrium model analysis of economywide cross effects of social and environmental policies in Chile. Ecological Economics, 54(4):447-472.

Rausch, S., Metcalf, G. E., and Reilly, J. M. (2011). Distributional impacts of carbon pricing: A general equilibrium approach with micro-data for households. Energy Economics, 33:20-33.

Rausch, S. and Mowers, M. (2014). Distributional and efficiency impacts of clean and renewable energy standards for electricity. Resource and Energy Economics, 36(2):556-585.

Sterner, T. (2012). Distributional effects of taxing transport fuel. Energy Policy, 41:75-83.

Yusuf, A. A. and Resosudarmo, B. P. (2008). Mitigating Distributional Impact of Fuel Pricing Reform: The Indonesian Experience. ASEAN Economic Bulletin, 25(1):32-47. 


\section{A The PACE model in more detail}

\section{A.1 The PACE model}

The PACE model is a GTAPingAMS CGE model ${ }^{4}$ with extensions that make it suitable for the analysis of climate and energy policies at a global scale. In each region, representative households own (region specific) production factors that are employed by the regional sectors for producing globally traded commodities. Regional governments that collect tax revenues, demand government services, and make transfers to households round off the picture. The introduction of five representative consumers per European member state is the crucial extension to the standard PACE model made by this paper. The five representative households represent income quintiles and both their expenditure and their income are calibrated by using survey data from European member states.

The production factors owned by the representative households are labour, capital, and resources (viz. the fossil fuels crude oil, gas, and coal). Those are priced at $\mathrm{PE}_{L}, \mathrm{PE}_{K}, \mathrm{PR}_{\text {res }}$ (res=col, cru, gas). Labour and capital are mobile between sectors within countries. Solely for power generation is capital technology specific and in fixed supply. The five technologies for power generation are oil, gas, coal, renewables, and nuclear and the corresponding types of fixed capital are priced at $\mathrm{PRT}_{t e c}(t e c=$ oil, gas, coal, renewable, nuclear). The five representative households in each region consume their specific consumption bundles $g_{C_{1}}, \ldots, g_{C_{5}}$ and demand fixed amounts of the investment good $g_{I}$. Another agent in each region which represents the government levies taxes, issues subsidies, makes transfers to households, and demands fixed amounts of government services $g_{G}$.

The factors owned by households are employed by industrial sectors (see Table 3 for an enumeration of sectors) to produce sector specific outputs ${ }^{5}$ which are traded between regions and used as intermediate inputs by other sectors and are also consumed by representative agents.

PACE uses nested CES production functions to represent production in different economic sectors, trade, and final consumption. The standard production function (see also Fig. 5 in the Appendix) combines the use of intermediates (priced at $\mathrm{PA}_{r, i, g}$ ) with a value added-energy composite at the top level. The value added-energy composite combines a labour-capital nest with the energy composite. The latter again combines electricity (ele) input with a col-(oil-gas) aggregate. In order to account for carbon taxation, all fossil fuel inputs to the energy composite are associated with the amount of $\mathrm{CO}_{2}$ emitted by the burning of the fuels. This production structure applies to all productive sectors (including production of non-traded commodities

\footnotetext{
${ }^{4}$ See for example https://www.gtap.agecon.purdue.edu/about/data_models.asp

${ }^{5}$ Throughout the paper sectors and their specific commodity shall carry the same identifier $i$.
} 
Table 3: Sectors of the PACE model. The last column lists the indices that include the respective sector. Index $g$ runs over all goods and consumption bundles, $i$ over traded goods, $f$ over fossil fuels, res over resources, ets over sectors covered by the EU ETS, and nets sectors outside the ETS. The distinction between ets and nets is only relevant for EU member states.

\begin{tabular}{rlll}
\hline Code & Sector & \multicolumn{2}{l}{ In indices } \\
\hline oil & refined coal and coal products & \multicolumn{2}{l}{$g, i, f, \quad$ ets } \\
gas & natural gas products & $g, i, f$, res, nets \\
omn & mining and construction & $g, i$, & nets \\
ppp & Paper-pulp-print & $g, i$, & ets \\
crp & Chemical-Rubber-Plastic products & $g, i$, & ets \\
nmm & Mineral products nec & $g, i$, & ets \\
i.s & Ferrous metals & $g, i$, & ets \\
nfm & Metals nec & $g, i$, & ets \\
ele & Electricity and heat & $g, i$, & nets \\
col & Coal transformation & $g, i, f$, res, nets \\
cru & Crude Oil & $g, i$, res, nets \\
mch & Machinery and other manufacturing & $g, i$, & nets \\
faw & Food agriculture wood & $g, i$, & nets \\
twl & Textiles-wearing apparel-leather & $g, i$, & nets \\
trn & Transport & $g, i$, & nets \\
ser & Services & $g, i$, & nets \\
$g_{I}$ & Investment & $g$, & nets \\
$g_{G}$ & Government consumption & $g$, & nets \\
$g_{C_{5}}$ & Household consumption & $g$, & nets \\
\hline
\end{tabular}


Table 4: Regions of the PACE model.

\begin{tabular}{|c|c|c|c|}
\hline \multicolumn{2}{|l|}{ EU } & \multicolumn{2}{|c|}{ non-EU } \\
\hline Code & Region & Code & Region \\
\hline Aut & Austria & $\mathrm{CHN}$ & China \\
\hline BEL & Belgium & JAP & Japan \\
\hline BGR & Bulgaria & KoR & South Korea \\
\hline $\mathrm{HRV}$ & Croatia & IDN & Indonesia \\
\hline CYP & Cyprus & IND & India \\
\hline $\mathrm{CzE}$ & Czech Republic & CAN & Canada \\
\hline DNK & Denmark & UsA & USA \\
\hline EsT & Estonia & MEX & Mexico \\
\hline Fin & Finland & BRA & Brazil \\
\hline FrA & France & Rus & Russia \\
\hline DEU & Germany & AnZ & Australia and New Zealand \\
\hline GRC & Greece & RAX & Rest of Annex-I \\
\hline HuN & Hungary & Row & Rest of World \\
\hline IRL & Ireland & & \\
\hline ITA & Italy & & \\
\hline Lva & Latvia & & \\
\hline LTU & Lithuania & & \\
\hline Lux & Luxembourg & & \\
\hline MLt & Malta & & \\
\hline NLD & Netherlands & & \\
\hline POL & Poland & & \\
\hline PRT & Portugal & & \\
\hline Rou & Romania & & \\
\hline SVK & Slovakia & & \\
\hline SvN & Slovenia & & \\
\hline EsP & Spain & & \\
\hline Swe & Sweden & & \\
\hline GBR & United Kingdom & & \\
\hline
\end{tabular}


Table 5: Production factors and commodities of the PACE model.

\begin{tabular}{|c|c|c|}
\hline Commodity & Price & Indices \\
\hline Endowments & $\mathrm{PE}_{r, e}$ & $\begin{array}{l}r=\text { Aut, Bel, Bgr, Hrv, } \\
\text { Cyp, Cze, Dnk, Est, Fin, } \\
\text { Fra, Deu, Gre, Hun, Irl, } \\
\text { Ita, Lva, Ltu, Lux, Mlt, } \\
\text { Nld, Pol, Prt, Rou, Svk, } \\
\text { Svn, Esp, Swe, Gbr, } \\
\text { Chn, Jap, Kor, Idn, Ind, } \\
\text { CAn, UsA, Mex, Bra, Rus, } \\
\text { Anz, Rax, Row } \\
e=K, L\end{array}$ \\
\hline Specific capital & $\mathrm{PRT}_{r, t e c}$ & $\begin{aligned} r, t e c & =\text { oil, gas, coal, } \\
& \text { renewable, nuclear }\end{aligned}$ \\
\hline Resources & $\mathrm{PR}_{r, r e s}$ & $r, r e s=\mathrm{col}, \mathrm{cru}, \mathrm{gas}$ \\
\hline Purchased goods & $\mathrm{PA}_{r, i, g}$ & $\begin{array}{l}r, i=\text { oil, gas, omn, ppp } \\
\text { crp, nmm, i_s, nfm, ele, col, } \\
\text { cru, mch, faw, twl, trn, ser }\end{array}$ \\
\hline Imported goods & $\mathrm{PM}_{r, i}$ & $r, i$ \\
\hline Output & $\mathrm{P}_{r, g}$ & $\begin{array}{l}r, g=\text { oil, gas, omn, ppp } \\
\text { crp, nmm, i_s, nfm, ele, col, } \\
\text { cru, mch, faw, twl, trn, ser, } \\
g_{I}, g_{G}, g_{C_{1}}, \ldots, g_{C_{5}}\end{array}$ \\
\hline
\end{tabular}


Table 6: Taxes and subsidies in the PACE model. rto, rtf, rtfd, rtfi, rtxs, and rtms are fix tax rates implied by SAM data. GFSUB, XI, and PSI are endogenously determined by the model.

\begin{tabular}{llll}
\hline Tax rate & Taxed value & Taxed sector & Tax collector \\
\hline $\mathrm{rto}_{r, g}-\mathrm{GFSUB}_{r, g}$ & $\mathrm{P}_{r, g}$ & $\mathrm{Y}_{r, g \neq \text { ele }}$ & Government $r$ \\
$\mathrm{rto}_{r, \text { ele }}+\mathrm{XI}_{r}-\mathrm{PSI}_{r}^{t e c}$ & $\mathrm{P}_{r, \text { ele }}$ & $\mathrm{Y}_{r, c \text { ele }}^{\text {tec }}$ & Government $r$ \\
$\operatorname{rtf}_{r, g, \mathrm{~K}}$ & $\mathrm{PE}_{r, \mathrm{~K}}$ & $\mathrm{Y}_{r, g \neq \text { ele }}$ & Government $r$ \\
$\mathrm{rtf}_{r, g, \mathrm{~L}}$ & $\mathrm{PE}_{r, \mathrm{~L}}$ & $\mathrm{Y}_{r, g}^{\text {tec }}$ & Government $r$ \\
$\mathrm{rtf}_{r, r e s, \mathrm{R}}$ & $\mathrm{PR}_{r, r e s}$ & $\mathrm{Y}_{r, r e s}$ & Government $r$ \\
$\mathrm{rtf}_{r, i, g}$ & $\mathrm{P}_{r, i}$ & $\mathrm{~A}_{r, i, g}$ & Government $r$ \\
$\operatorname{rtfi}_{r, i, g}$ & $\mathrm{PM}_{r, i}$ & $\mathrm{~A}_{r, i, g}$ & Government $r$ \\
$\operatorname{rtxs}_{r^{\prime}, r, i}$ & $\mathrm{P}_{r^{\prime}, i}$ & $\mathrm{M}_{r, i}$ & Government $r^{\prime}$ \\
$\operatorname{rtms}_{r^{\prime}, r, i} \cdot\left(1-\mathrm{rtxs}_{r^{\prime}, r, i}\right)$ & $\mathrm{P}_{r^{\prime}, i}$ & $\mathrm{M}_{r, i}$ & Government $r$ \\
$\operatorname{rtms}_{r^{\prime}, r, i}$ & $\mathrm{PT}^{(a)}$ & $\mathrm{M}_{r, i}$ & Government $r$ \\
\hline
\end{tabular}

(a) International transportation priced at PT is required for the importing activity $\mathrm{M}_{r, i}$ for transporting the commodity $i$ from different regions $r^{\prime}$. The tax rate $\mathrm{rtms}_{r^{\prime}, r, i}$ applies to the part of transportation that is needed to import the good from region $r^{\prime}$.

for investment $g_{I}$, government consumption $g_{G}$, and private consumption by households of the different quintiles $g_{C_{1}}, \ldots, g_{C_{5}}$ ), except power generation and extraction of fossil fuels. In the case of power generation, the model distinguishes the five generation technologies oil, gas, coal, renewable, and nuclear. Each of them provides the homogeneous good that represents electricity services and that is traded at price $\mathrm{P}_{r \text {,ele }}$. The production technologies differ in fuel and capital intensity, each technology using its specific fossil fuel and capital type. The technologies combine non-capital inputs in fixed proportions (according to a Leontief production function) and trade them off with the technology specific capital stock. This trade-off happens at an elasticity of substitution that allows for calibration of price elasticity of electricity supply per technology (also see Fig. 6 in the Appendix). In the case of fossil fuel extraction, the fuel specific resource priced at $\mathrm{PR}_{r, r e s}$ is used together with non-resource inputs in fixed proportions (extraction) and this composite can be traded off against more of the non-resource inputs (exploration) at a positive elasticity of substitution on the top level (see Fig. 7 in the Appendix).

The output of industry $i$ thus produced in region $r$ (priced at $\mathrm{P}_{r, i}$ ) is then either exported or sold to sector/agent $g^{6}$ on the domestic market, alongside with the imported version of the good (priced at $\mathrm{PM}_{r, i}$ ). Both

\footnotetext{
${ }^{6}$ Index $g$ runs over both industries $i$ and agents $g_{C_{1}}, g_{C_{5}}, g_{G}, g_{I}$ that are identified with the same index as the commodity they consume
} 
are traded off against each other according to the Armington assumption, which results in a domestic market price index $\mathrm{PA}_{r, i, g}$ (display a of Fig. 8). The imported version of the good is again an aggregate of the varieties that are produced in other regions. They reach the market of region $r$ by using international transport services (priced at PT), which are provided from domestic transport services according to a Cobb-Douglas production function (displays b and c of Fig. 8).

Taxes in PACE are levied on production factors and final products. Countries levy tariffs on imports and subsidise exports. Carbon taxes (for meeting emission targets outside the EU ETS) and emission allowance expenses (allowances are issued for sectors whose emissions are governed by the EU ETS) are both proportional to the amount of fossil fuels burned in the process of energy generation. $\mathrm{CO}_{2}$ emission rights are in both cases modelled as a commodity in fixed supply. Regarding emissions within the EU ETS, the market clearing price for such emission rights (the model prices them at $\left.\mathrm{PC}^{\text {ets }}\right)$ corresponds to the market price of ETS allowances. Outside the EU ETS, the modelled market price $\left(\mathrm{PC}_{r}^{\text {nets }}\right)$ for emission rights corresponds to the $\mathrm{CO}_{2}$ tax that governments would have to impose on emitters in order to efficiently meet their national targets. The emission rights are owned by the national governments, and revenues from selling them are given to households via lump-sum transfers or are invested, depending on the policy scenario.

PACE is implemented as a mixed complementarity program (MCP) using MPS/GE. As such, it consists of a set of equations with each equation complementing exactly one variable of the model. The MCP framework implies that, at a solution, equations may be violated such that the left-hand sides are bigger (smaller) than the right-hand sides if their complementary variables are at their lower (upper) bounds. The standard set of equations in CGE models consists of

- zero-profit conditions (cost $\geq$ revenue) for each sector (thus determining the non-negative activity level of the sector),

- market clearing conditions (supply $\geq$ demand) for each commodity (thus determining the non-negative market price of the commodity), and

- budget balance conditions (spending $=$ income) for each representative agent (thus determining the consumption expenditure by that representative agent).

In order to derive the aforementioned equations from production structures, the model assumes that inputs are chosen such that production costs are minimised. When producers take market prices of inputs as given, unit factor demand and unit production cost can be derived in closed form from 
the nested CES production functions. Thus, zero-profit conditions can be constructed by using unit production cost. In addition, unit factor demand multiplied by sectoral activity gives sectoral factor demand, which is needed to formulate market balance equations (and via the tax channel into income balance of governments). Appendix A.2 provides more detailed information on this.

Besides the aforementioned standard equations, additional equations are needed to determine the output subsidy $\mathrm{GFSUB}_{r, \text { ets }}$ for sectors ets that receive free allowances in the ETS. The subsidy for sector ets is set in such a way that the value of the subsidy, which flows into the sector, cancels the expenditure that the sector incurs for the permits it should receive freely. This has the two desired effects that, on the one hand side, cost minimising fuel demand of sectors includes permit cost and thus reflects the opportunity cost of holding carbon permits for own use, and, on the other hand, sectors do not pass on permit cost to consumers. This corresponds to the assumption that under perfect competition windfall profits from freely allocated permits will make firms enter the sector until market prices for the produced commodity have dropped to a level where profits correspond to the average regional returns on capital. In stylised form, the equation complementary to the positive variable $\mathrm{GFSUB}_{r, \text { ets }}$ is

$$
\text { GFSUB }_{r, \text { ets }} \cdot \text { revenue }_{r, \text { ets }} \geq \text { freeshare }_{\text {ets }} \cdot \text { permit-expenditure }_{r, \text { ets }} \text {. }
$$

freeshare $_{\text {ets }}$ is a sector specific share of allowances that is allocated to the sector ets for free and 'revenue $r, e t s$ ' and 'permit-expenditure ${ }_{r, e t s}$ ' are endogenously determined by the model.

In some scenarios, a target for the share of power generation from RES in total electricity shall be reached by implementing a quota. To meet the quota, the power sector, representing the operators of different generation technologies, subsidises power from RES with the rate $\mathrm{PSI}_{r}$. Thus, its subsidised generation cost can compete with the generation cost of other technologies even at the required high deployment rates of RES. The additional costs are financed with share $\mathrm{XI}_{r}$ of total power sales, which is modelled as an internally raised sales tax rate $\mathrm{XI}_{r}$. The stylised equations complementary to the two positive variables $\mathrm{PSI}_{r}$ and $\mathrm{XI}_{r}$ are

$$
\begin{aligned}
& \text { power supply }_{r, \text { renewables }} \geq \text { renshare }_{r} \cdot \sum_{t e c} \text { power supply }_{r, t e c} \\
& \text { and } \\
& \mathrm{XI}_{r} \cdot \sum_{t e c} \text { power sales }_{r, t e c} \geq \mathrm{PSI}_{r} \cdot \text { generation cost }_{r, \text { renewables }} \cdot
\end{aligned}
$$

The parameter renshare ${ }_{r}$ is given by the policy scenario, and 'power supply $r, t e c$ ', 'power sales $r, t e c$ ', and 'generation cost $_{r, t e c}$ ' are endogenously determined by the model. 
Real government consumption of good $g_{G}$ is kept constant by the model. Lump-sum transfers from the government to the households are adjusted by the unconstrained variable $\mathrm{RTAX}_{r}$ in the case of a budget surplus or deficit to solve

$$
\bar{Y}_{r, g_{G}}=Y_{r, g_{G}} .
$$

In order to keep track of revenues from auctioning permits in the EU ETS, the model needs to distinguish between the amount of emission allowances allocated to sectors for free (FREEEUAS $r$ ) within region $r$ and those that are auctioned (AUCTEUAS $r$ ) by the government $r$. The two equations that are complementary to these positive variables are

$$
\begin{aligned}
& \text { FREEEUAS }_{r} \geq \sum_{\text {ets }} \text { freeshare }_{\text {ets }} \cdot \text { permit-demand }_{r, \text { ets }}, \\
& \text { AUCTEUAS }_{r} \geq \text { auctshare }_{r} \cdot\left(\text { etscap }-\sum_{r} \text { FREEEUAS }_{r}\right),
\end{aligned}
$$

where 'etscap', 'freeshare $e_{\text {ets }}$, and 'auctshare ${ }_{r}$ ' are exogenous parameters and 'permit-demand ${ }_{r, e t s}$ ' is endogenously determined by the model. 'etscap' is the European ETS cap and 'auctshare ${ }_{r}$ ' shares the revenue of permit auctioning among member states $r\left(\sum_{r}\right.$ auctshare $\left._{r}=1\right)$.

In some scenarios, national governments are required to spend their revenue from permit auctioning on investments. In that case, the positive variable INVDEM ${ }_{r}$ denotes the additional demand for the investment good $g_{I}$ that is caused by this. It is complementary to the equation

$$
\mathrm{INVDEM}_{r} \geq \mathrm{PC}^{\text {ets }} \cdot \mathrm{AUCTEUAS}_{r} .
$$




\section{A.2 Structure of production and trade in the PACE model}

The PACE model employs nested production functions depicted in Figure 5, where each node represents a CES nest with the child nodes as inputs and the associated $\sigma^{\mathrm{NODE}}$ as the elasticities of substitution governing the CES nest 'NODE'. The appendix illustrates how such trees correspond to nested CES production functions and how unit expenditure functions and unit factor demand functions are derived.

Activity $\mathbf{Y}_{r, g}(g \neq$ ele,$g \neq r e s)$ :

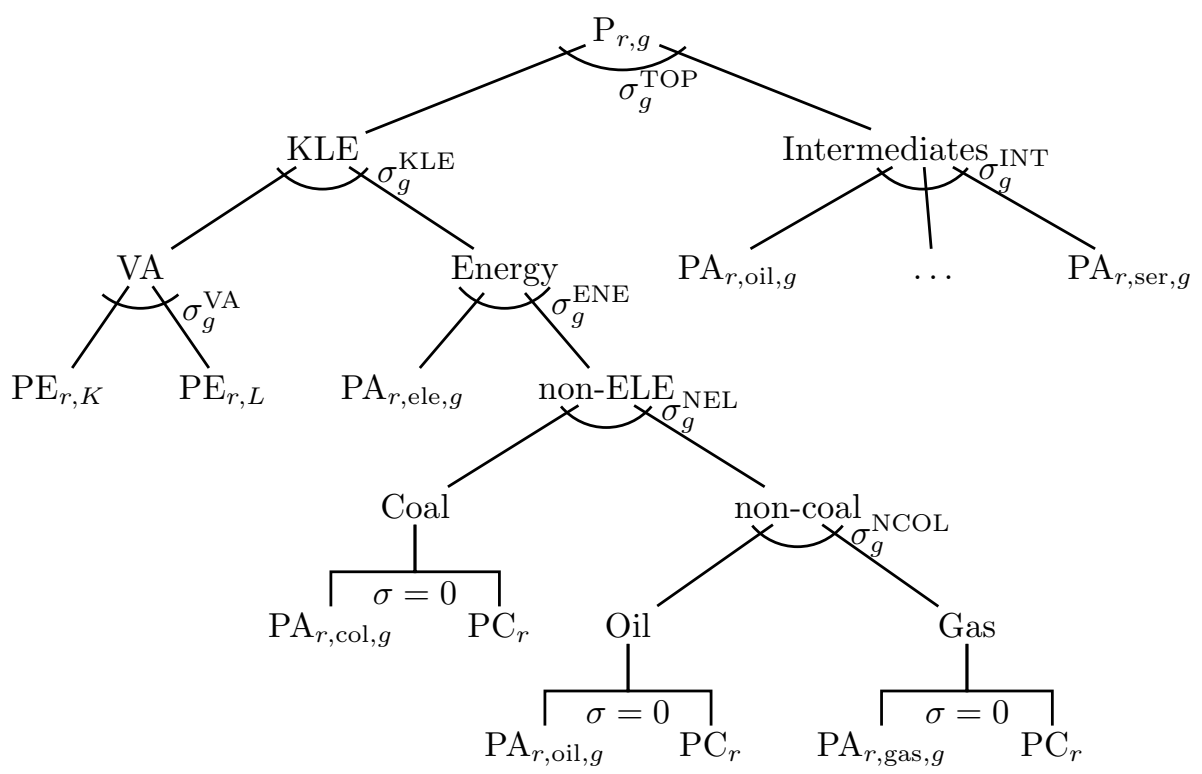

Figure 5: Production of commodity $g$ in region $r$ for all $g$ other than electricity $(g=$ ele) and resources $(g=\mathrm{col}$, cru, gas). The Intermediates nest does not use commodities $i=$ ele, col, gas, as these enter the Energy nest exclusively. The commodity $i=$ oil only enters the Intermediates nest with positive quantities in the case of oil refineries $g=$ oil. 
Activity $\mathbf{Y}_{r, \text { ele }}^{t e c}$ :

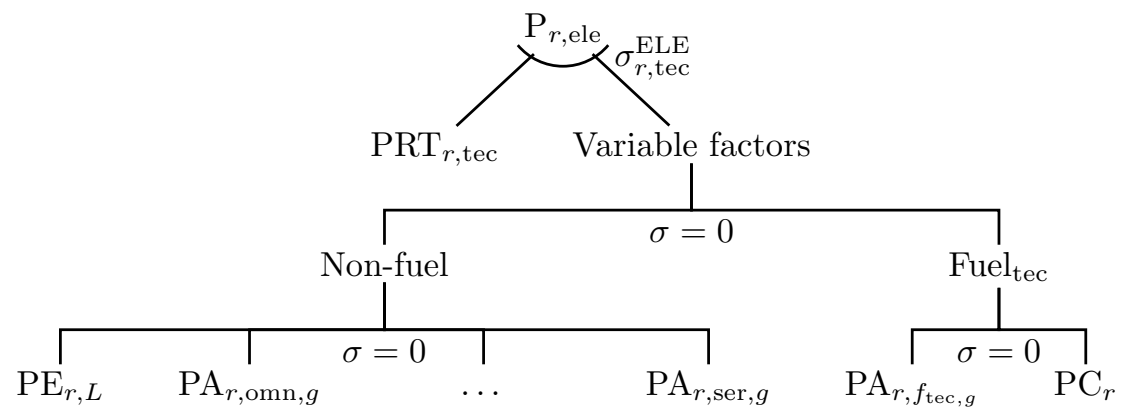

Figure 6: Power generation by technology 'tec'. Capital used in power generation is modelled as a technology specific factor priced at $\mathrm{PRT}_{r, t e c}$ that is not mobile across sectors. The variable factors include technology specific fuels $f_{\text {tec }}\left(f_{\text {oil }}=\right.$ oil, $f_{\text {gas }}=$ gas, $f_{\text {coal }}=$ col $)$ on the one hand, and nonfuel variable inputs on the other. Non-fuel variable inputs are used in the same fixed proportions for all power generation technologies.

Activity $\mathbf{Y}_{r, \text { res }}$ :
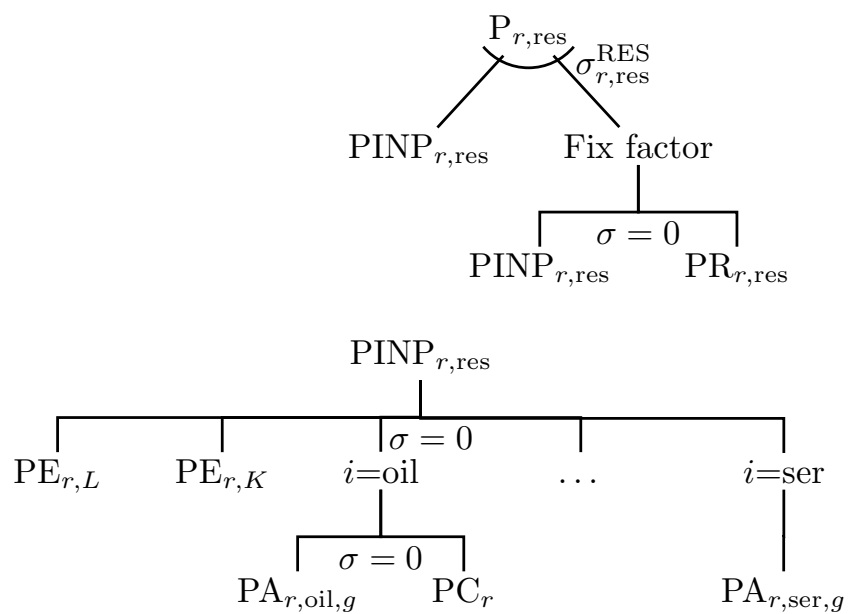

Figure 7: Production function for extraction of resources res priced at $\mathrm{P}_{r, \text { res }}$. Production inputs are used in fixed proportions to produce an intermediary

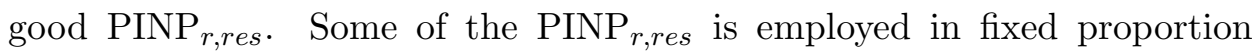
with the resource capacity $\mathrm{PR}_{r, \text { res }}$ itself, the rest enters production at the top-level nest which allows some degree of substitution between production efforts and resource availability. 
(a) Activity $\mathbf{A}_{r, i, g}$ :

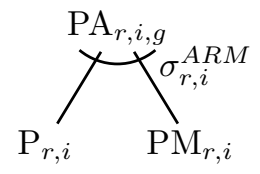

(b) Activity $\mathbf{M}_{r, i}$ :

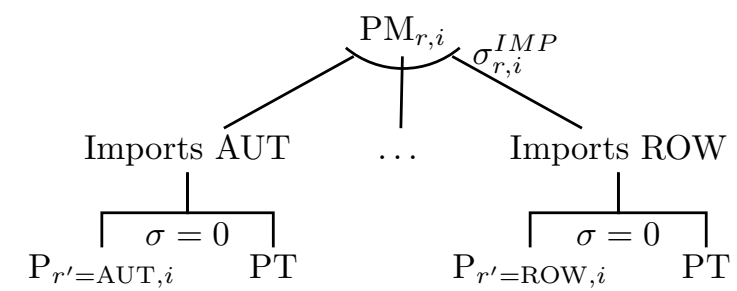

(c) Activity YT:

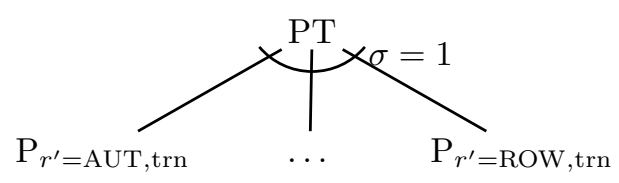

Figure 8: Armington aggregate and imports. Traded commodities $i$ are purchased by production sectors and consumers in region $r$ at price $\mathrm{PA}_{r, i, g}$. This price is the result of trade-off between the domestically produced version of the good priced at $\mathrm{P}_{r, i}$, and the imported version priced at $\mathrm{PM}_{r, i}$. The price of the imported version of the good is the result of trading off imports from different trade partners $r^{\prime}\left(r^{\prime}=\mathrm{AUT}, \ldots, \mathrm{ROW}\right)$ priced at $\mathrm{P}_{r^{\prime}, i}$. Additionally, importing from one region to another requires fixed amounts of international transport services priced at $\mathrm{PT}$ and provided by activity YT. 


\section{A.3 From nested CES functions to model equations}

Let the CES production function

$$
\hat{Y}=\left[\sum_{i=1}^{k} \theta_{i}\left(\hat{I}_{i}\right)^{\frac{\sigma-1}{\sigma}}\right]^{\frac{\sigma}{\sigma-1}}
$$

describe the production of $Y$ from inputs $I_{i}(i=1, \ldots, k)$ if $\hat{V}$ denotes the value of a variable $V$ relative to its benchmark value $\bar{V}$ to which the CES production function is calibrated. Given benchmark inputs $\bar{I}_{i}$ and benchmark prices $\bar{P}_{I_{i}}, \theta_{i}$ shall denote the value share of good $i$ in benchmark production

$$
\theta_{i}=\frac{\bar{I}_{i} \bar{P}_{I_{i}}}{\sum_{j=1}^{k} \bar{I}_{j} \bar{P}_{I_{j}}} .
$$

In analogy to the following, this guarantees that benchmark input quantities correspond to cost minimising input demand for production at benchmark prices $\bar{P}_{i}$. Then, if prices of $I_{i}$ are $P_{I_{i}}$, minimised unit production cost can be shown to be

$$
\hat{e}\left(P_{I_{1}}, \ldots, P_{I_{k}}\right)=\left[\sum_{i=1}^{k} \theta_{i}\left(\hat{P}_{I_{i}}\right)^{1-\sigma}\right]^{\frac{1}{1-\sigma}} .
$$

If the zero profit condition is met, and the market price of commodity $Y$, $P_{Y}$, equals unit expenditure $\left(\hat{P}_{Y}=\hat{e}\right)$, the price minimising unit demand can be written as

$$
\begin{aligned}
d_{i}\left(P_{I_{1}}, \ldots, P_{I_{k}}\right) & =\frac{\partial e\left(P_{I_{1}}, \ldots, P_{I_{k}}\right)}{\partial P_{i}} \\
& =\frac{\bar{e} \theta_{i}}{\bar{P}_{I_{i}}}\left(\frac{\hat{e}\left(P_{I_{1}}, \ldots, P_{I_{k}}\right)}{\hat{P}_{I_{i}}}\right)^{\sigma} .
\end{aligned}
$$
forms

In the special cases $\sigma=1$ and $\sigma=0$, the production function takes the

$$
\begin{array}{ll}
\hat{Y}=\prod_{i=1}^{k}\left(\hat{I}_{i}\right)^{\theta_{i}} & \sigma=1 \\
\hat{Y}=\min _{i=1}^{k}\left(\hat{I}_{i}\right) & \sigma=0
\end{array}
$$

and the minimised unit production cost is

$$
\begin{array}{ll}
\hat{e}\left(P_{1}, \ldots, P_{k}\right)=\prod_{i=1}^{k}\left(\hat{P}_{I_{i}}\right)^{\theta_{i}} & \sigma=1 \\
\hat{e}\left(P_{1}, \ldots, P_{k}\right)=\sum_{i=1}^{k} \theta_{i} \hat{P}_{I_{i}} & \sigma=0 .
\end{array}
$$


The following equations illustrate how the nested CES tree in Figure 5 corresponds to CES production functions and how taxes in Table 6 of the paper enter the corresponding unit cost and demand functions. In order to keep track of cost of sub-nests, internal prices are introduced and $p_{\text {NEST }}$ shall denote the unit cost of sub-nest NEST. The zero-profit conditions which are complementary to $\mathrm{Y}_{r, g}$ and relate the market prices $\mathrm{P}_{r, g}$ with the input prices $\mathrm{PA}_{r, i, g}, \mathrm{PE}_{r, \mathrm{~K}}, \mathrm{PE}_{r, \mathrm{~L}}$, the carbon prices $\mathrm{PC}_{r}^{\text {nets }}$ and $\mathrm{PC}^{\text {ets }}$, and the sub-nest costs $p_{\mathrm{KLE}, r, g}, p_{\mathrm{VA}, r, g}, p_{\mathrm{ENE}, r, g}, p_{\mathrm{NEL}, r, g}, p_{\mathrm{NCOL}, r, g}$ and $p_{\mathrm{INT}, r, g}$ are

$$
\begin{aligned}
& \hat{\mathrm{P}}_{r, g}\left[1-\mathrm{rto}_{r, g}+\mathrm{GFSUB}_{r, g}\right]^{\wedge} \\
& \leq\left[\theta_{r, g}^{\mathrm{KLE}}\left(\hat{p}_{\mathrm{KLE}, r, g}\right)^{1-\sigma_{g}^{\mathrm{TOP}}}+\theta_{r, g}^{\mathrm{INT}}\left(\hat{p}_{\mathrm{INT}, r, g}\right)^{1-\sigma_{g}^{\mathrm{TOP}}}\right]^{\frac{1}{1-\sigma_{g}^{\mathrm{TOP}}}} \\
& \hat{p}_{\mathrm{INT}, r, g}=\left[\sum_{i} \theta_{\mathrm{INT}, r, g}^{i}\left(\hat{\mathrm{PA}}_{r, i, g}\right)^{1-\sigma_{g}^{\mathrm{INT}}}\right]^{\frac{1}{1-\sigma_{g}^{\mathrm{INT}}}} \\
& \hat{p}_{\mathrm{KLE}, r, g}=\left[\theta_{\mathrm{KLE}, r, g}^{\mathrm{VA}}\left(\hat{p}_{\mathrm{VA}, r, g}\right)^{1-\sigma_{g}^{\mathrm{KLE}}}+\theta_{\mathrm{KLE}, r, g}^{\mathrm{ENE}}\left(\hat{p}_{\mathrm{ENE}, r, g}\right)^{1-\sigma_{g}^{\mathrm{KLE}}}\right]^{\frac{1}{1-\sigma_{g}^{\mathrm{KLE}}}} \\
& \hat{p}_{\mathrm{VA}, r, g}=\left[\theta_{\mathrm{VA}, r, g}^{\mathrm{K}}\left(\hat{\mathrm{PE}}_{r, \mathrm{~K}}\left[1+\mathrm{rtf}_{r, g, \mathrm{~K}}\right]^{\wedge}\right)^{1-\sigma_{g}^{\mathrm{VA}}}\right. \\
& \left.+\theta_{\mathrm{VA}, r, g}^{\mathrm{L}}\left(\hat{\mathrm{PE}}_{r, \mathrm{~L}}\left[1+\operatorname{rtf}_{r, g, \mathrm{~L}}\right]^{\wedge}\right)^{1-\sigma_{g}^{\mathrm{VA}}}\right]^{\frac{1}{1-\sigma_{g}^{\mathrm{VA}}}} \\
& \hat{p}_{\mathrm{ENE}, r, g}=\left[\theta_{\mathrm{ENE}, r, g}^{\mathrm{ele}}\left(\hat{\mathrm{PA}}_{r, \mathrm{ele}, g}\right)^{1-\sigma_{g}^{\mathrm{ENE}}}+\theta_{\mathrm{ENE}, r, g}^{\mathrm{NEL}}\left(\hat{p}_{r, \mathrm{NEL}}\right)^{1-\sigma_{g}^{\mathrm{ENE}}}\right]^{\frac{1}{1-\sigma_{g}^{\mathrm{ENE}}}} \\
& \hat{p}_{\mathrm{NEL}, r, g}=\left[\theta_{\mathrm{NEL}, r, g}^{\mathrm{col}}\left(\left[\mathrm{PA}_{r, \mathrm{col}, g}+\xi_{r, \mathrm{col}, g} \mathrm{PC}_{r}^{\mathrm{ets} / \mathrm{nets}}\right] \wedge\right)^{1-\sigma_{g}^{\mathrm{NEL}}}\right. \\
& \left.+\theta_{\mathrm{NEL}, r, g}^{\mathrm{NCOL}}\left(\hat{p}_{r, \mathrm{NCOL}}\right)^{1-\sigma_{g}^{\mathrm{NEL}}}\right]^{\frac{1}{1-\sigma_{g}^{\mathrm{NEL}}}} \\
& \hat{p}_{\mathrm{NCOL}, r, g}=\left[\theta_{\mathrm{NCOL}, r, g}^{\mathrm{oil}}\left(\left[\mathrm{PA}_{r, \mathrm{oil}, g}+\xi_{r, \mathrm{oil}, g} \mathrm{PC}_{r}^{\mathrm{ets} / \mathrm{nets}}\right] \wedge\right)^{1-\sigma_{g}^{\mathrm{NCOL}}}\right. \\
& \left.+\theta_{\mathrm{NCOL}, r, g}^{\mathrm{gas}}\left(\left[\mathrm{PA}_{r, \mathrm{gas}, g}+\xi_{r, \mathrm{gas}, g} \mathrm{PC}_{r}^{\mathrm{ets} / \mathrm{nets}}\right]\right)^{1-\sigma_{g}^{\mathrm{NCOL}}}\right]^{\frac{1}{1-\sigma_{g}^{\mathrm{NCOL}}}},
\end{aligned}
$$

where $\xi_{r, i, g}$ are the emission coefficients of inputs $i$ to production process $g$ and $\theta_{\text {NEST }}^{\text {INPUT }}$ are the value shares of INPUT in nest NEST such that the shares of inputs within a nest add up to one. The emission coefficients are calculated by dividing the benchmark emissions caused by the burning of the input by the benchmark value of inputs $i$ to $g$. 
If supply of the good priced at $\mathrm{P}_{r, g}$ by sector $g$ in region $r$ is $\mathrm{S}_{r, g}$, demands $d_{\mathrm{INT}, r, g}$ and $d_{\mathrm{KLE}, r, g}$ for the INT and KLE nest outputs are determined by

$$
\begin{aligned}
\hat{d}_{\mathrm{INT}, r, g} & =\hat{\mathrm{S}}_{r, g}\left(\frac{\hat{\mathrm{P}}_{r, g}\left[1-\mathrm{rto}_{r, g}+\mathrm{GFSUB}_{r, g}\right]^{\wedge}}{\hat{p}_{\mathrm{INT}, r, g}}\right)^{\sigma_{g}^{\mathrm{TOP}}} \\
\hat{d}_{\mathrm{KLE}, r, g} & =\hat{\mathrm{S}}_{r, g}\left(\frac{\hat{\mathrm{P}}_{r, g}\left[1-\mathrm{rto}_{r, g}+\mathrm{GFSUB}_{r, g}\right]^{\wedge}}{\hat{p}_{\mathrm{KLE}, r, g}}\right)^{\sigma_{g}^{\mathrm{TOP}}} .
\end{aligned}
$$

From this, demand $\mathrm{DA}_{r, i, g}$ for the intermediate good priced at $\mathrm{PA}_{r, i, g}$ by the INT nest is derived as

$$
\begin{aligned}
\hat{\mathrm{DA}}_{r, i, g ; \mathrm{INT}} & =\hat{d}_{\mathrm{INT}, r, g}\left(\frac{\hat{p}_{\mathrm{INT}, r, g}}{\mathrm{PA}_{r, i, g}}\right)^{\sigma_{g}^{\mathrm{INT}}} \\
& =\hat{\mathrm{S}}_{r, g}\left(\frac{\hat{\mathrm{P}}_{r, g}\left[1-\mathrm{rto}_{r, g}+\mathrm{GFSUB}_{r, g}\right]^{\wedge}}{\hat{p}_{\mathrm{INT}, r, g}}\right)^{\sigma_{g}^{\mathrm{TOP}}}\left(\frac{\hat{p}_{\mathrm{INT}, r, g}}{\hat{\mathrm{PA}}_{r, i, g}}\right)^{\sigma_{g}^{\mathrm{INT}}},
\end{aligned}
$$

and in analogy, demand for labour and capital by sector $g$ in region $r$ is given by

$$
\begin{aligned}
\hat{\mathrm{DE}}_{\mathrm{L} / \mathrm{K}, r ; g}= & \hat{\mathrm{S}}_{r, g}\left(\frac{\hat{\mathrm{P}}_{r, g}\left[1-\mathrm{rto}_{r, g}+\mathrm{GFSUB}_{r, g}\right]^{\wedge}}{\hat{p}_{\mathrm{KLE}, r, g}}\right)^{\sigma_{g}^{\mathrm{TOP}}}\left(\frac{\hat{p}_{\mathrm{KLE}, r, g}}{\hat{p}_{\mathrm{VA}, r, g}}\right)^{\sigma_{g}^{\mathrm{KLE}}} \\
& \cdot\left(\frac{\hat{p}_{\mathrm{VA}, r, g}}{\hat{\mathrm{PE}}_{r, \mathrm{~L} / \mathrm{K}}\left[1+\mathrm{rtf}_{r, g, \mathrm{~L} / \mathrm{K}}\right]^{\wedge}}\right)^{\sigma_{g}^{\mathrm{VA}}} \cdot
\end{aligned}
$$

Demands for coal ( $\left.\mathrm{DA}_{r, \mathrm{col}, g ; \mathrm{ENE}}\right)$ as an energy input and for emission permits associated with coal $\left(\mathrm{DC}_{r ; \mathrm{col}, g}\right)$ use are

$$
\begin{aligned}
\hat{\mathrm{DA}}_{r, \mathrm{col}, g ; \mathrm{ENE}}= & \hat{\mathrm{S}}_{r, g}\left(\frac{\hat{\mathrm{P}}_{r, g}\left[1-\mathrm{rto}_{r, g}+\mathrm{GFSUB}_{r, g}\right]^{\wedge}}{\hat{p}_{\mathrm{KLE}, r, g}}\right)^{\sigma_{g}^{\mathrm{TOP}}}\left(\frac{\hat{p}_{\mathrm{KLE}, r, g}}{\hat{p}_{\mathrm{ENE}, r, g}}\right)^{\sigma_{g}^{\mathrm{KLE}}} \\
& \cdot\left(\frac{\hat{p}_{\mathrm{ENE}, r, g}}{\hat{p}_{\mathrm{NEL}, r, g}}\right)^{\sigma_{g}^{\mathrm{ENE}}}\left(\frac{\hat{p}_{\mathrm{NEL}, r, g}}{\left[\mathrm{PA}_{r, \mathrm{col}, g}+\xi_{r, \mathrm{col}, g} \mathrm{PC}_{r}^{\mathrm{ets} / \mathrm{nets}}\right] \uparrow}\right)^{\sigma_{g}} \\
\hat{\mathrm{DC}}_{r ; \mathrm{col}, g}= & \hat{\mathrm{DA}}_{r, \mathrm{col}, g ; \mathrm{ENE}} .
\end{aligned}
$$

Demand for other commodities by all sectors is derived in analogy to the above following the demand structures given in Figures 5-8. Table 7 gives an overview as to which activities supply and demand which commodities in PACE. Market clearance conditions follow directly. 
Table 7: Overview over demand and supply of commodities

\begin{tabular}{|c|c|c|}
\hline Price & Supply (proportional to) & Demand (proportional to) \\
\hline $\mathrm{P}_{r, i}$ & $\mathrm{~S}_{r, i}^{(t e c)}\left(\mathrm{Y}_{r, i}^{(t e c)}\right)$ & $\begin{aligned} \mathrm{D}_{r, i ; A} & \left(\mathrm{~A}_{r, i, g}\right) \\
\mathrm{D}_{r, i ; M, s} & \left(\mathrm{M}_{s, i}\right) \\
\mathrm{D}_{r, i=\operatorname{trn} ; Y T} & (\mathrm{YT})\end{aligned}$ \\
\hline $\mathrm{P}_{r, g_{C_{1 \ldots 5}}}$ & $\mathrm{~S}_{r, g_{C_{1 \ldots 5} \ldots}}\left(\mathrm{Y}_{r, g_{C_{1 \ldots 5} \ldots}}\right)$ & $\mathrm{D}_{r, g_{C_{1 \ldots 5}}}\left(\frac{\mathrm{HH}_{r, C_{1 \ldots 5}}}{\mathrm{P}_{r, g_{C_{1}, 5}}}\right)$ \\
\hline $\mathrm{P}_{r, g_{I}}$ & $\mathrm{~S}_{r, g_{I}}\left(\mathrm{Y}_{r, g_{I}}\right)$ & $\overline{\mathrm{D}}_{r, g_{I}}$ \\
\hline $\mathrm{P}_{r, g_{G}}$ & $\mathrm{~S}_{r, g_{G}}\left(\mathrm{Y}_{r, g_{G}}\right)$ & $\mathrm{D}_{r, g_{G}}\left(\frac{\mathrm{GOVT}_{r}}{\mathrm{P}_{r, g_{G}}}\right)$ \\
\hline $\mathrm{PE}_{r, \mathrm{~L} / \mathrm{K}}$ & $\overline{\mathrm{SE}}_{r, \mathrm{~L} / \mathrm{K}}$ & $\mathrm{DE}_{r, \mathrm{~L} / \mathrm{K} ; i}\left(\mathrm{Y}_{r, i}^{(t e c)}\right)$ \\
\hline $\mathrm{PRT}_{r, t e c}$ & $\overline{\mathrm{SRT}}_{r, t e c}$ & $\operatorname{DRT}_{r, \text { tec }}\left(\mathrm{Y}_{r, \mathrm{ele}}^{\text {tec }}\right)$ \\
\hline $\mathrm{PR}_{r, r e s}$ & $\overline{\mathrm{SR}}_{r, r e s}$ & $\mathrm{DR}_{r, r e s}\left(\mathrm{Y}_{r, r e s}\right)$ \\
\hline $\mathrm{PA}_{r, i, g}$ & $\mathrm{SA}_{r, i, g}\left(\mathrm{~A}_{r, i, g}\right)$ & $\begin{array}{l}\mathrm{DA}_{r, i, g ; \mathrm{INT}}\left(\mathrm{Y}_{r, g}\right) \\
\mathrm{DA}_{r, i, g ; \mathrm{ENE}}\left(\mathrm{Y}_{r, g}\right)\end{array}$ \\
\hline $\mathrm{PM}_{r, i}$ & $\mathrm{SM}_{r, i}\left(\mathrm{M}_{r, i}\right)$ & $\mathrm{DM}_{r, i ; g}\left(\mathrm{~A}_{r, i, g}\right)$ \\
\hline $\mathrm{PT}$ & $\mathrm{ST}(\mathrm{YT})$ & $\mathrm{DT}_{r, i}\left(\mathrm{M}_{r, i}\right)$ \\
\hline $\mathrm{PC}_{r}^{\text {nets }}$ & $\overline{\mathrm{SC}}_{r}$ & $\mathrm{DC}_{r ; f, \text { nets }}\left(\mathrm{Y}_{r, \text { nets }}\right)$ \\
\hline $\mathrm{PC}_{r}^{\text {ets }}$ & $\begin{array}{c}\sum_{r}\left(\text { AUCTEUAS }_{r}\right. \\
\left.+ \text { FREEEUAS }_{r}\right)\end{array}$ & $\mathrm{DC}_{r ; f, e t s}\left(\mathrm{Y}_{r, e t s}\right)$ \\
\hline
\end{tabular}

Income balance equations have to hold for the government and each income quintile per regions:

$$
\begin{aligned}
& \mathrm{GOVT}_{r}=\mathrm{PC}_{r}^{\text {nets }} \overline{\mathrm{SC}}_{r}+\mathrm{PC}_{r}^{\text {ets }} \mathrm{AUCTEUAS}_{r}-\mathrm{RTAX}_{r} \\
& +\mathrm{PC}_{r}^{\text {ets }} \text { FREEEUAS }_{r}-\sum_{i} \operatorname{GFSUB}_{r, i} \mathrm{P}_{r, i} \mathrm{~S}_{r, i} \\
& +\sum_{i} \operatorname{rto}_{r, i} \mathrm{P}_{r, i} \mathrm{~S}_{r, i}+\sum_{i, r^{\prime}} \operatorname{rtxs}_{r, r^{\prime}, i} \mathrm{P}_{r, i} \mathrm{D}_{r, i ; M, r^{\prime}} \\
& +\sum_{i, r^{\prime}} \operatorname{rtms}_{r^{\prime}, r, i}\left[\left(1-\operatorname{rtxs}_{r^{\prime}, r, i}\right) \mathrm{P}_{r^{\prime}, i} \mathrm{D}_{r^{\prime}, i ; M, r}+\mathrm{PT} \cdot \mathrm{DT}_{r, i}\right]+ \\
& +\sum_{i, e} \operatorname{rtf}_{r, i, e} \mathrm{PE}_{r, e} \mathrm{DE}_{r, e ; i}+\sum_{r e s} \operatorname{rtf}_{r, r e s, \mathrm{R}} \mathrm{PR}_{r, r e s} \mathrm{DR}_{r, r e s} \\
& +\sum_{i, g} \operatorname{rtfd}_{r, i, g} \mathrm{P}_{r, i} \mathrm{D}_{r, i ; A}+\sum_{i, g} \operatorname{rtfi}_{r, i, g} \mathrm{PM}_{r, i} \mathrm{DM}_{r, i ; g} \\
& \mathrm{HH}_{r, C_{q}}=\kappa_{r, q}\left[\mathrm{PE}_{r, \mathrm{~K}} \overline{\mathrm{SE}}_{r, \mathrm{~K}}+\sum_{t e c} \mathrm{PRT}_{r, t e c} \overline{\mathrm{SRT}}_{r, t e c}+\sum_{r e s} \mathrm{PR}_{r, r e s} \overline{\mathrm{SR}}_{r, r e s}\right] \\
& +\lambda_{r, q} \mathrm{PE}_{r, \mathrm{~L}} \overline{\mathrm{SE}}_{r, \mathrm{~L}}-\kappa_{r, q} \mathrm{P}_{r, g_{I}} \overline{\mathrm{D}}_{r, g_{I}}+\tau_{r, q} \mathrm{RTAX}_{r} \quad q=1, \ldots, 5 .
\end{aligned}
$$




\section{A.4 Data}

The data source for the calibration of PACE originates from the GTAP (Aguiar et al., 2012). Version 8.1 of the GTAP data base provides the model with input output structures for production sectors as well as trade patterns.

In order to capture impacts of rising prices of energy commodities on consumers with different levels of affluence in different countries, we disaggregate the representative household of each country into five households that represent the income quintiles. We combine two sets of survey results to split expenditures on the one and income on the other hand between the quintiles. On the expenditure side, national expenditures for different consumption goods have to be split into the expenditure of different income quintiles $q=1, \ldots, 5$. The resulting expenditures will be used to calibrate the nested CES functions representing the consumption activities $\mathrm{Y}_{g_{C_{q}}}$ which yield the final consumption baskets denoted by commodities $g_{C_{1}}, \ldots, g_{C_{5}}$. On the income side, factor endowments and government transfers have to be realistically distributed among quintiles in the benchmark. While endowments are fixed quantities in the model, transfers are endogenously determined in the scenarios. In these scenarios, changes from benchmark transfers will be distributed among the quintiles in proportion to the initial benchmark transfers.

\section{Expenditure of income quintiles}

The model imitates information from Eurostat on the amount of overall consumption and the share of the energy goods in overall consumption for each quintile. It is worthwhile to note that we rely on household expenditures in PPS provided by Eurostat in order to make consumption bundles comparable between member states when reporting results. The household budget surveys of EUROSTAT (2014) provide expenditures per household and per adult equivalent for five quintiles in all EU member states for the year 2010. Also on the quintile level, consumption is split into different broad consumer good categories at the tow-digit level of the Classification of Individual Consumption According to Purpose (COICOP). On the national level, Eurostat splits consumption into more detailed consumer good categories which makes it possible to identify the consumption of the energy goods electricity, liquid fuels for heating and transportation, gas, and coal.

In order to distribute consumption of energy good $i i$ among quintiles, its share in national consumption of the two-digit category $i$ containing $i i$ is used to split each quintile's consumption of category $i$ into its parts. Call $\sigma_{i i, t o t}^{\text {national }}$ the share of $i i$ consumption in total expenditures at the national level. Similarly, $\sigma_{i, t o t}^{q}$ is defined as the share of $i$ consumption in total ex- 
penditures of quintile $q$. With these two definitions given by Eurostat, we compute the shares

$$
\sigma_{i i, i}^{\text {national }}=\sigma_{i i, t o t}^{\text {national }} / \sigma_{i, t o t}^{\text {national }}
$$

for energy goods $i i$ contained in categories $i$, and guess the share of good $i i$ consumption in total expenditure of quintile $q$ to be

$$
\sigma_{i i, t o t}^{q}=\sigma_{i, t o t}^{q} \sigma_{i i, i}^{\text {national }}
$$

The Eurostat tables provide numbers for the years 2010, 2005, 1999, and previous ones. Unavailable entries for 2005 and 2010 were imputed from 1999 or 2005 entries. This was done either by scaling them according to the next higher category which was available, or otherwise by assuming a growth of consumption according to the national growth of GDP across quintiles and categories.

Expenditure shares for energy goods in GTAP do not necessarily match expenditure shares found in the household surveys by Eurostat. We focus on energy commodities and use Eurostat survey results to distribute both total expenditures and expenditures for energy commodities realistically across quintiles. Total consumption expenditures of the representative household in GTAP are distributed among quintiles according to expenditure per household divided by the estimated household size ${ }^{7}$ within the income quintiles defined by Eurostat household surveys. The expenditures on energy commodities $i i$ is split across quintiles in proportion to

$$
\frac{\sigma_{i i, t o t}^{q} \varepsilon^{q}}{\sum_{q^{\prime}} \sigma_{i i, t o t}^{q^{\prime}} \varepsilon^{q^{\prime}}},
$$

\footnotetext{
${ }^{7}$ By comparing household expenditures per adult equivalent with household expenditures per household, we infer the number of adult equivalents per household in each quintile. Adult equivalents as a measure of household size are computed by counting the head of a household with weight 1 and adding 0.5 for each additional adult and 0.3 for each additional child in the same household. In the extreme case in which all members of all households are adults, the average household size $n$ is

$$
n=1+\frac{a e-1}{0.5},
$$

if ae denotes the average number of adult equivalents per household. In the other extreme case in which all households consist of one adult plus children,

$$
n=1+\frac{a e-1}{0.3} .
$$

An intermediate estimator for the household size that fits the national average household size across countries relatively well is

$$
n=1+2.3(a e-1) .
$$
}


where $\varepsilon^{q}$ denote total expenditures of households within quintiles. Expenditures for non-energy commodities are distributed in fixed proportions among quintiles so that expenditures for energy and non-energy commodities add up to total expenditures.

\section{Income of quintiles in PACE}

On the income side, the PACE model distinguishes between wage earnings, rents on capital and resources, and net transfers from government to households which are not necessarily positive.

In order to split these revenue streams among income quintiles, the HFCS by the ECB is consulted. The data are available for the following $15 \mathrm{mem}-$ bers of the eurozone: Austria, Belgium, Cyprus, Germany, Spain, Finland, France, Greece, Italy, Luxembourg, Malta, Netherlands, Portugal, Slovenia, and Slovakia. We group these countries into Western, Eastern, and Southern Europe and assume that in the remaining EU member states, factor incomes are distributed across households according to the European area (viz. South, East, or West) that they belong to. Thus, of the member states not included in the HFCS , Bulgaria, Czech Republic, Estonia, Latvia, Lithuania, Hungary, Poland, and Romania are included in the Eastern European region. Croatia is part of Southern Europe. Denmark, Ireland, Sweden, and the United Kingdom are included in Western Europe.

Income classes of the HFCS are split into the broad fields wages, capital income, pensions, and transfers. The PACE model on the other hand, distinguishes labour income, rents from capital, income from resources, and transfers from the government to households or vice versa.

Transfers in GTAP and the HFCS don't seem to have congruent meanings (in the ECB surveys, transfers principally result in positive income, whereas they can also have a negative impact on households' balance sheets in GTAP). The PACE benchmark calibration uses total (national) transfers regardless of their sign and distributes them among quintiles $q$ in proportion to the always positive transfer revenue indicated by the HFCS with shares $\tau_{r, q} \cdot{ }^{8}$

From the remaining revenue flows of households in GTAP, labour income is identified with labour income in the HFCS survey, while capital and resource rents are identified with revenues from capital and pensions. This reflects the fact that capital rents in GTAP by far exceed pure capital income according to the HFCS and can be defended by acknowledging that pensions, at least to some extent, constitute rents on earlier investments.

Shares $\kappa_{r, q}$ of the national revenue $\bar{K}_{r}$ from capital and resources available according to GTAP are attributed to the income quintiles $q=1, \ldots, 5$

\footnotetext{
${ }^{8}$ If national governments transfer additional revenue from climate policies to households, transfers to quintiles in PACE change in proportion to benchmark transfers. The implemented calibration guarantees that the benefits from these additional transfers going to different quintiles are distributed in proportion to transfers in the ECB survey data.
} 
and similarly, national wage earnings $\bar{L}_{r}$ are distributed according to shares $\lambda_{r, q}$. The revenues from the respective shares of $\bar{K}_{r}$ and $\bar{L}_{r}$ have to add up to the income quintiles' factor income $\mathrm{FI}_{r, q}$. For our purpose, this factor income is the residual between the income quintiles' expenditure and the benchmark government transfers allocated to them as described above. In order to achieve a good match between the shares of capital or labour income in any quintile's average household income in the PACE calibration and the shares of capital-plus-pension income $\left(\operatorname{cpis}_{r, q}\right)$ or labour income $\left(\operatorname{lis}_{r, q}\right)$ in any quintiles average household income according to the HFCS, the following optimisation was evaluated

$$
\begin{aligned}
\min _{\kappa_{r, 1}, \ldots, \kappa_{r, 5}, \lambda_{r, 1}, \ldots, \lambda_{r, 5}} & \sum_{r, q}\left[\left(\frac{\kappa_{r, q} \bar{K}_{r}}{\mathrm{FI}_{r, q}}-\operatorname{cpis}_{r, q}\right)^{8}+\left(\frac{\lambda_{r, q} \bar{L}_{r}}{\mathrm{FI}_{r, q}}-\operatorname{lis}_{r, q}\right)^{8}\right] \\
\text { s.t. } 1 & =\sum_{q} \kappa_{r, q} \quad \forall r \\
1 & =\sum_{q} \lambda_{r, q} \quad \forall r \\
\mathrm{FI}_{r, q} & =\kappa_{r, q} \bar{K}_{r}+\lambda_{r, q} \bar{L}_{r} \quad \forall(r, q) .
\end{aligned}
$$




\section{B Member state results in more detail}

Table 8: Results for Austria, Belgium, and Bulgaria (annual consumption expenditure of different income quintiles in Purchasing Power Standard (PPS)) 
Table 9: Results for Croatia, Cyprus, the Czech Republic, Denmark, and Estonia (annual consumption expenditure of different income quintiles in PPS)

\begin{tabular}{|c|c|c|c|c|c|c|c|}
\hline & & overall & q1 & q2 & q3 & $\mathrm{q} 4$ & q5 \\
\hline \multirow[t]{9}{*}{ HRV } & NoPolicy & 9’632 & $6 ’ 345$ & $8^{\prime} 609$ & $9^{\prime} 724$ & $10^{\prime} 674$ & $12^{\prime} 776$ \\
\hline & Cap & $-0.54 \%$ & $-0.61 \%$ & $-0.52 \%$ & $-0.44 \%$ & $-0.40 \%$ & $-0.71 \%$ \\
\hline & $C a p+R E S$ & $-0.53 \%$ & $-0.90 \%$ & $-0.56 \%$ & $-0.44 \%$ & $-0.34 \%$ & $-0.51 \%$ \\
\hline & Invest & $-0.93 \%$ & $-1.50 \%$ & $-0.95 \%$ & $-0.76 \%$ & $-0.62 \%$ & $-0.95 \%$ \\
\hline & Invest $+R E S$ & $-0.75 \%$ & $-1.38 \%$ & $-0.80 \%$ & $-0.61 \%$ & $-0.46 \%$ & $-0.64 \%$ \\
\hline & ТaxCap & $-0.55 \%$ & $0.55 \%$ & $-0.33 \%$ & $-0.63 \%$ & $-0.88 \%$ & $-1.13 \%$ \\
\hline & TaxCap+RES & $-0.54 \%$ & $0.27 \%$ & $-0.37 \%$ & $-0.62 \%$ & $-0.81 \%$ & $-0.93 \%$ \\
\hline & NoPolicy - pl & 9’632 & 63345 & $8^{\prime} 606$ & $9^{\prime} 722$ & $10^{\prime} 673$ & $12^{\prime} 783$ \\
\hline & $C a p-\mathrm{pl}$ & $-0.54 \%$ & $-0.58 \%$ & $-0.44 \%$ & $-0.40 \%$ & $-0.39 \%$ & $-0.87 \%$ \\
\hline \multirow[t]{9}{*}{ CYP } & NoPolicy & $24^{\prime} 166$ & $13 ' 349$ & $19 ' 885$ & $24 ’ 315$ & $26 ’ 924$ & $36^{\prime} 521$ \\
\hline & Cap & $-0.90 \%$ & $-0.92 \%$ & $-0.66 \%$ & $-0.56 \%$ & $-0.66 \%$ & $-1.46 \%$ \\
\hline & $C a p+R E S$ & $-0.86 \%$ & $-1.23 \%$ & $-0.80 \%$ & $-0.69 \%$ & $-0.60 \%$ & $-1.04 \%$ \\
\hline & Invest & $-1.47 \%$ & $-1.97 \%$ & $-1.30 \%$ & $-1.14 \%$ & $-1.04 \%$ & $-1.87 \%$ \\
\hline & Invest $+R E S$ & $-1.17 \%$ & $-1.79 \%$ & $-1.14 \%$ & $-1.00 \%$ & $-0.81 \%$ & $-1.27 \%$ \\
\hline & ТaxCap & $-0.90 \%$ & $-0.03 \%$ & $-0.63 \%$ & $-0.53 \%$ & $-1.06 \%$ & $-1.65 \%$ \\
\hline & TaxCap+RES & $-0.86 \%$ & $-0.32 \%$ & $-0.76 \%$ & $-0.66 \%$ & $-1.01 \%$ & $-1.23 \%$ \\
\hline & NoPolicy - pl & $24 ' 166$ & $13 ’ 349$ & $19 ' 885$ & $24^{\prime} 315$ & $26^{\prime} 924$ & $36^{\prime} 520$ \\
\hline & $C a p-\mathrm{pl}$ & $-0.90 \%$ & $-0.84 \%$ & $-0.64 \%$ & $-0.56 \%$ & $-0.68 \%$ & $-1.50 \%$ \\
\hline \multirow[t]{9}{*}{ CZE } & NoPolicy & 8'334 & 6'006 & 7’431 & $8^{\prime} 253$ & 9’044 & $10 ’ 966$ \\
\hline & Cap & $0.49 \%$ & $2.00 \%$ & $0.77 \%$ & $0.34 \%$ & $0.17 \%$ & $-0.63 \%$ \\
\hline & $C a p+R E S$ & $0.29 \%$ & $1.03 \%$ & $0.41 \%$ & $0.18 \%$ & $0.12 \%$ & $-0.22 \%$ \\
\hline & Invest & $-1.33 \%$ & $-1.50 \%$ & $-1.15 \%$ & $-0.98 \%$ & $-1.13 \%$ & $-1.82 \%$ \\
\hline & Invest $+R E S$ & $-0.71 \%$ & $-0.88 \%$ & $-0.64 \%$ & $-0.54 \%$ & $-0.58 \%$ & $-0.88 \%$ \\
\hline & ТaxCap & $0.49 \%$ & $2.20 \%$ & $0.79 \%$ & $0.28 \%$ & $0.09 \%$ & $-0.71 \%$ \\
\hline & TaxCap+RES & $0.29 \%$ & $1.24 \%$ & $0.42 \%$ & $0.13 \%$ & $0.05 \%$ & $-0.30 \%$ \\
\hline & NoPolicy - pl & 8'334 & $6^{\prime} 003$ & $7^{\prime} 430$ & $8^{\prime} 253$ & $9^{\prime} 045$ & $10 ’ 971$ \\
\hline & $C a p-\mathrm{pl}$ & $0.49 \%$ & $2.01 \%$ & $0.77 \%$ & $0.34 \%$ & $0.17 \%$ & $-0.64 \%$ \\
\hline \multirow[t]{9}{*}{ DNK } & NoPolicy & $19^{\prime} 212$ & 14’032 & $16{ }^{\prime} 877$ & 19'142 & $21^{\prime} 091$ & $24^{\prime} 938$ \\
\hline & Cap & $-0.66 \%$ & $-1.01 \%$ & $-0.77 \%$ & $-0.62 \%$ & $-0.43 \%$ & $-0.53 \%$ \\
\hline & $C a p+R E S$ & $-1.02 \%$ & $-1.46 \%$ & $-1.13 \%$ & $-0.98 \%$ & $-0.76 \%$ & $-0.81 \%$ \\
\hline & Invest & $-0.91 \%$ & $-1.51 \%$ & $-1.07 \%$ & $-0.84 \%$ & $-0.55 \%$ & $-0.64 \%$ \\
\hline & Invest $+R E S$ & $-1.15 \%$ & $-1.73 \%$ & $-1.29 \%$ & $-1.10 \%$ & $-0.83 \%$ & $-0.87 \%$ \\
\hline & ТахСар & $-0.66 \%$ & $-0.57 \%$ & $-0.66 \%$ & $-0.66 \%$ & $-0.64 \%$ & $-0.78 \%$ \\
\hline & Tax Cap+RES & $-1.02 \%$ & $-1.02 \%$ & $-1.01 \%$ & $-1.02 \%$ & $-0.97 \%$ & $-1.06 \%$ \\
\hline & NoPolicy - pl & $19^{\prime} 212$ & $14^{\prime} 032$ & $16^{\prime} 877$ & 19'142 & $21^{\prime} 092$ & $24^{\prime} 939$ \\
\hline & Cap - pl & $-0.66 \%$ & $-0.77 \%$ & $-0.60 \%$ & $-0.56 \%$ & $-0.50 \%$ & $-0.88 \%$ \\
\hline \multirow[t]{9}{*}{ EST } & NoPolicy & 6’768 & 3’930 & $5 ’ 462$ & 5745 & 7’710 & $11^{\prime} 021$ \\
\hline & Cap & $-0.12 \%$ & $3.43 \%$ & $1.05 \%$ & $0.24 \%$ & $-0.52 \%$ & $-2.57 \%$ \\
\hline & Cap $+R E S$ & $-0.18 \%$ & $1.70 \%$ & $0.48 \%$ & $0.08 \%$ & $-0.36 \%$ & $-1.57 \%$ \\
\hline & Invest & $-3.07 \%$ & $-3.00 \%$ & $-2.57 \%$ & $-2.27 \%$ & $-2.65 \%$ & $-4.21 \%$ \\
\hline & Invest $+R E S$ & $-1.80 \%$ & $-1.82 \%$ & $-1.50 \%$ & $-1.28 \%$ & $-1.53 \%$ & $-2.49 \%$ \\
\hline & ТахCap & $-0.12 \%$ & $3.72 \%$ & $1.17 \%$ & $0.25 \%$ & $-0.61 \%$ & $-2.74 \%$ \\
\hline & Tax Cap+RES & $-0.18 \%$ & $1.99 \%$ & $0.60 \%$ & $0.09 \%$ & $-0.45 \%$ & $-1.74 \%$ \\
\hline & NoPolicy - pl & 6'768 & 3'922 & $5 ` 457$ & $5 ’ 745$ & $7 ’ 711$ & $11^{\prime} 037$ \\
\hline & $C a p-\mathrm{pl}$ & $-0.12 \%$ & $3.69 \%$ & $1.17 \%$ & $0.24 \%$ & $-0.53 \%$ & $-2.77 \%$ \\
\hline
\end{tabular}


Table 10: Results for Finland, France, Germany, Greece, and Hungary (annual consumption expenditure of different income quintiles in PPS)

\begin{tabular}{|c|c|c|c|c|c|c|c|}
\hline & & overall & q1 & $\mathrm{q} 2$ & q3 & $\mathrm{q} 4$ & $\mathrm{q} 5$ \\
\hline \multirow[t]{9}{*}{ FIN } & NoPolicy & $18^{\prime} 114$ & $11^{\prime} 250$ & $14^{\prime} 897$ & $17^{\prime} 669$ & 20’319 & $26^{\prime} 461$ \\
\hline & Cap & $-0.34 \%$ & $-0.23 \%$ & $-0.25 \%$ & $-0.27 \%$ & $-0.35 \%$ & $-0.54 \%$ \\
\hline & $C a p+R E S$ & $-0.30 \%$ & $-0.40 \%$ & $-0.30 \%$ & $-0.25 \%$ & $-0.24 \%$ & $-0.30 \%$ \\
\hline & Invest & $-0.71 \%$ & $-0.96 \%$ & $-0.74 \%$ & $-0.62 \%$ & $-0.62 \%$ & $-0.69 \%$ \\
\hline & Invest $+R E S$ & $-0.50 \%$ & $-0.80 \%$ & $-0.57 \%$ & $-0.44 \%$ & $-0.39 \%$ & $-0.39 \%$ \\
\hline & ТaxCap & $-0.34 \%$ & $0.09 \%$ & $-0.12 \%$ & $-0.29 \%$ & $-0.48 \%$ & $-0.72 \%$ \\
\hline & $T a x C a p+R E S$ & $-0.30 \%$ & $-0.08 \%$ & $-0.17 \%$ & $-0.27 \%$ & $-0.37 \%$ & $-0.48 \%$ \\
\hline & NoPolicy - pl & $18^{\prime} 114$ & $11^{\prime} 246$ & $14^{\prime} 891$ & $17^{\prime} 665$ & $20^{\prime} 322$ & $26^{\prime} 477$ \\
\hline & Cap - pl & $-0.34 \%$ & $-0.27 \%$ & $-0.29 \%$ & $-0.30 \%$ & $-0.33 \%$ & $-0.46 \%$ \\
\hline \multirow[t]{9}{*}{ FRA } & NoPolicy & $18 ' 100$ & $12 ’ 031$ & $15^{\prime} 116$ & $17^{\prime} 253$ & $20 ’ 029$ & $26^{\prime} 081$ \\
\hline & Сар & $-0.09 \%$ & $-0.26 \%$ & $-0.14 \%$ & $-0.10 \%$ & $-0.05 \%$ & $0.01 \%$ \\
\hline & $C a p+R E S$ & $-0.14 \%$ & $-0.39 \%$ & $-0.21 \%$ & $-0.15 \%$ & $-0.07 \%$ & $0.02 \%$ \\
\hline & Invest & $-0.20 \%$ & $-0.49 \%$ & $-0.27 \%$ & $-0.20 \%$ & $-0.10 \%$ & $-0.04 \%$ \\
\hline & Invest $+R E S$ & $-0.19 \%$ & $-0.51 \%$ & $-0.28 \%$ & $-0.20 \%$ & $-0.10 \%$ & $0.00 \%$ \\
\hline & ТахCap & $-0.09 \%$ & $0.02 \%$ & $-0.09 \%$ & $-0.12 \%$ & $-0.16 \%$ & $-0.10 \%$ \\
\hline & $T a x C a p+R E S$ & $-0.14 \%$ & $-0.10 \%$ & $-0.16 \%$ & $-0.18 \%$ & $-0.18 \%$ & $-0.08 \%$ \\
\hline & NoPolicy - pl & $18^{\prime} 100$ & $12^{\prime} 030$ & $15^{\prime} 116$ & $17^{\prime} 253$ & $20 ’ 029$ & $26^{\prime} 082$ \\
\hline & Cap - pl & $-0.09 \%$ & $-0.28 \%$ & $-0.15 \%$ & $-0.11 \%$ & $-0.04 \%$ & $0.03 \%$ \\
\hline \multirow[t]{9}{*}{ DEU } & NoPolicy & $19^{\prime} 247$ & $11^{\prime} 313$ & $15^{\prime} 545$ & $18^{\prime} 544$ & $21^{\prime} 441$ & $29^{\prime} 411$ \\
\hline & Сap & $-0.13 \%$ & $0.01 \%$ & $-0.09 \%$ & $-0.13 \%$ & $-0.15 \%$ & $-0.23 \%$ \\
\hline & $C a p+R E S$ & $-0.13 \%$ & $-0.24 \%$ & $-0.08 \%$ & $-0.07 \%$ & $-0.13 \%$ & $-0.17 \%$ \\
\hline & Invest & $-0.41 \%$ & $-0.64 \%$ & $-0.45 \%$ & $-0.36 \%$ & $-0.32 \%$ & $-0.37 \%$ \\
\hline & Invest $+R E S$ & $-0.29 \%$ & $-0.60 \%$ & $-0.28 \%$ & $-0.19 \%$ & $-0.22 \%$ & $-0.25 \%$ \\
\hline & ТахCap & $-0.13 \%$ & $0.44 \%$ & $-0.03 \%$ & $-0.22 \%$ & $-0.28 \%$ & $-0.34 \%$ \\
\hline & $T a x C a p+R E S$ & $-0.14 \%$ & $0.21 \%$ & $-0.02 \%$ & $-0.16 \%$ & $-0.27 \%$ & $-0.29 \%$ \\
\hline & NoPolicy - pl & $19^{\prime} 247$ & 11'312 & $15^{\prime} 541$ & $18^{\prime} 540$ & $21^{\prime} 442$ & $29^{\prime} 421$ \\
\hline & Cap - pl & $-0.13 \%$ & $0.02 \%$ & $-0.07 \%$ & $-0.12 \%$ & $-0.15 \%$ & $-0.26 \%$ \\
\hline \multirow[t]{9}{*}{ GRC } & NoPolicy & $17^{\prime} 073$ & $10 ' 704$ & $12^{\prime} 471$ & $15 ’ 311$ & $18^{\prime} 571$ & $28^{\prime} 331$ \\
\hline & Cap & $-1.09 \%$ & $-1.42 \%$ & $-1.15 \%$ & $-0.97 \%$ & $-1.01 \%$ & $-1.02 \%$ \\
\hline & $C a p+R E S$ & $-1.12 \%$ & $-1.85 \%$ & $-1.29 \%$ & $-0.96 \%$ & $-1.02 \%$ & $-0.86 \%$ \\
\hline & Invest & $-1.62 \%$ & $-2.65 \%$ & $-1.82 \%$ & $-1.35 \%$ & $-1.45 \%$ & $-1.28 \%$ \\
\hline & Invest $+R E S$ & $-1.41 \%$ & $-2.52 \%$ & $-1.66 \%$ & $-1.17 \%$ & $-1.26 \%$ & $-1.00 \%$ \\
\hline & ТахСар & $-1.09 \%$ & $1.82 \%$ & $-0.46 \%$ & $-1.57 \%$ & $-1.59 \%$ & $-2.17 \%$ \\
\hline & $T a x C a p+R E S$ & $-1.12 \%$ & $1.47 \%$ & $-0.58 \%$ & $-1.57 \%$ & $-1.61 \%$ & $-2.04 \%$ \\
\hline & NoPolicy - pl & $17^{\prime} 073$ & $10^{\prime} 701$ & $12^{\prime} 470$ & $15 ’ 311$ & $18^{\prime} 571$ & $28^{\prime} 337$ \\
\hline & Cap - pl & $-1.09 \%$ & $-1.46 \%$ & $-1.17 \%$ & $-0.97 \%$ & $-1.01 \%$ & $-0.99 \%$ \\
\hline \multirow[t]{9}{*}{ HUN } & NoPolicy & $6^{\prime} 833$ & $5 ’ 205$ & $5 ’ 927$ & 65569 & $7^{\prime} 376$ & 9'097 \\
\hline & Cap & $0.15 \%$ & $0.43 \%$ & $0.23 \%$ & $0.13 \%$ & $0.10 \%$ & $-0.06 \%$ \\
\hline & $C a p+R E S$ & $0.05 \%$ & $0.13 \%$ & $0.08 \%$ & $0.06 \%$ & $0.04 \%$ & $-0.02 \%$ \\
\hline & Invest & $-0.37 \%$ & $-0.50 \%$ & $-0.36 \%$ & $-0.28 \%$ & $-0.31 \%$ & $-0.41 \%$ \\
\hline & Invest $+R E S$ & $-0.23 \%$ & $-0.38 \%$ & $-0.25 \%$ & $-0.17 \%$ & $-0.18 \%$ & $-0.21 \%$ \\
\hline & ТахСар & $0.15 \%$ & $0.68 \%$ & $0.28 \%$ & $0.05 \%$ & $0.02 \%$ & $-0.17 \%$ \\
\hline & TaxCap+RES & $0.05 \%$ & $0.38 \%$ & $0.13 \%$ & $-0.02 \%$ & $-0.04 \%$ & $-0.13 \%$ \\
\hline & NoPolicy - pl & 6'833 & $5 ’ 204$ & $5^{\prime} 927$ & $6 ’ 569$ & $7^{\prime} 376$ & $9^{\prime} 098$ \\
\hline & Cap - pl & $0.15 \%$ & $0.45 \%$ & $0.24 \%$ & $0.13 \%$ & $0.10 \%$ & $-0.09 \%$ \\
\hline
\end{tabular}


Table 11: Results for Ireland, Italy, Latvia, Lithuania, and Luxembourg (annual consumption expenditure of different income quintiles in PPS)

\begin{tabular}{|c|c|c|c|c|c|c|c|}
\hline & & overall & q1 & q2 & q3 & $\mathrm{q} 4$ & q5 \\
\hline \multirow[t]{9}{*}{ IRL } & NoPolicy & $18^{\prime} 969$ & $14^{\prime} 588$ & $15^{\prime} 660$ & $17^{\prime} 502$ & $21^{\prime} 090$ & $26^{\prime} 015$ \\
\hline & Cap & $-0.17 \%$ & $-0.19 \%$ & $-0.17 \%$ & $-0.15 \%$ & $-0.13 \%$ & $-0.22 \%$ \\
\hline & $C a p+R E S$ & $-0.14 \%$ & $-0.26 \%$ & $-0.16 \%$ & $-0.12 \%$ & $-0.07 \%$ & $-0.10 \%$ \\
\hline & Invest & $-0.39 \%$ & $-0.61 \%$ & $-0.43 \%$ & $-0.35 \%$ & $-0.25 \%$ & $-0.34 \%$ \\
\hline & Invest $+R E S$ & $-0.25 \%$ & $-0.49 \%$ & $-0.31 \%$ & $-0.23 \%$ & $-0.13 \%$ & $-0.16 \%$ \\
\hline & ТахСар & $-0.17 \%$ & $0.15 \%$ & $-0.12 \%$ & $-0.20 \%$ & $-0.28 \%$ & $-0.34 \%$ \\
\hline & $T a x C a p+R E S$ & $-0.14 \%$ & $0.08 \%$ & $-0.11 \%$ & $-0.17 \%$ & $-0.22 \%$ & $-0.23 \%$ \\
\hline & NoPolicy - pl & $18^{\prime} 969$ & $14^{\prime} 584$ & $15^{\prime} 653$ & $17^{\prime} 499$ & $21^{\prime} 091$ & $26^{\prime} 030$ \\
\hline & Cap - pl & $-0.17 \%$ & $-0.17 \%$ & $-0.15 \%$ & $-0.14 \%$ & $-0.13 \%$ & $-0.25 \%$ \\
\hline \multirow[t]{9}{*}{ ITA } & NoPolicy & $17^{\prime} 971$ & $11^{\prime} 390$ & $14^{\prime} 387$ & $16^{\prime} 860$ & $19^{\prime} 722$ & $27^{\prime} 495$ \\
\hline & Сap & $-0.41 \%$ & $-0.47 \%$ & $-0.36 \%$ & $-0.35 \%$ & $-0.39 \%$ & $-0.45 \%$ \\
\hline & $C a p+R E S$ & $-0.34 \%$ & $-0.52 \%$ & $-0.32 \%$ & $-0.29 \%$ & $-0.33 \%$ & $-0.34 \%$ \\
\hline & Invest & $-0.64 \%$ & $-0.90 \%$ & $-0.60 \%$ & $-0.55 \%$ & $-0.61 \%$ & $-0.64 \%$ \\
\hline & Invest $+R E S$ & $-0.47 \%$ & $-0.75 \%$ & $-0.46 \%$ & $-0.39 \%$ & $-0.45 \%$ & $-0.44 \%$ \\
\hline & ТахСар & $-0.41 \%$ & $-0.12 \%$ & $-0.35 \%$ & $-0.43 \%$ & $-0.43 \%$ & $-0.52 \%$ \\
\hline & $T a x C a p+R E S$ & $-0.35 \%$ & $-0.16 \%$ & $-0.31 \%$ & $-0.36 \%$ & $-0.37 \%$ & $-0.40 \%$ \\
\hline & NoPolicy - pl & $17^{\prime} 971$ & $11^{\prime} 388$ & $14^{\prime} 385$ & $16 ’ 859$ & $19^{\prime} 722$ & $27^{\prime} 500$ \\
\hline & Cap - pl & $-0.41 \%$ & $-0.51 \%$ & $-0.38 \%$ & $-0.36 \%$ & $-0.39 \%$ & $-0.42 \%$ \\
\hline \multirow[t]{9}{*}{ LVA } & NoPolicy & 6'876 & $4 ' 527$ & $5^{\prime} 614$ & 6'138 & 7’362 & $10^{\prime} 710$ \\
\hline & Cap & $-0.15 \%$ & $-0.13 \%$ & $-0.16 \%$ & $-0.18 \%$ & $-0.15 \%$ & $-0.13 \%$ \\
\hline & $C a p+R E S$ & $-0.14 \%$ & $-0.33 \%$ & $-0.24 \%$ & $-0.19 \%$ & $-0.12 \%$ & $0.07 \%$ \\
\hline & Invest & $-0.67 \%$ & $-1.16 \%$ & $-0.77 \%$ & $-0.56 \%$ & $-0.54 \%$ & $-0.50 \%$ \\
\hline & Invest $+R E S$ & $-0.42 \%$ & $-0.89 \%$ & $-0.57 \%$ & $-0.40 \%$ & $-0.33 \%$ & $-0.14 \%$ \\
\hline & ТахСар & $-0.15 \%$ & $0.56 \%$ & $0.05 \%$ & $-0.24 \%$ & $-0.36 \%$ & $-0.47 \%$ \\
\hline & $T a x C a p+R E S$ & $-0.14 \%$ & $0.37 \%$ & $-0.03 \%$ & $-0.25 \%$ & $-0.33 \%$ & $-0.29 \%$ \\
\hline & NoPolicy - pl & 6'876 & $4 ' 524$ & $5^{\prime} 613$ & 6’138 & 7'362 & $10^{\prime} 714$ \\
\hline & Cap - pl & $-0.15 \%$ & $-0.18 \%$ & $-0.18 \%$ & $-0.18 \%$ & $-0.15 \%$ & $-0.09 \%$ \\
\hline \multirow[t]{9}{*}{ LTU } & NoPolicy & $8^{\prime} 672$ & $5^{\prime} 872$ & 7'294 & 8'449 & 9'529 & $12^{\prime} 227$ \\
\hline & Cap & $0.08 \%$ & $0.61 \%$ & $0.24 \%$ & $0.05 \%$ & $0.00 \%$ & $-0.29 \%$ \\
\hline & $C a p+R E S$ & $0.16 \%$ & $0.32 \%$ & $0.18 \%$ & $0.10 \%$ & $0.12 \%$ & $0.13 \%$ \\
\hline & Invest & $-0.76 \%$ & $-0.95 \%$ & $-0.72 \%$ & $-0.60 \%$ & $-0.66 \%$ & $-0.89 \%$ \\
\hline & Invest $+R E S$ & $-0.30 \%$ & $-0.53 \%$ & $-0.35 \%$ & $-0.25 \%$ & $-0.24 \%$ & $-0.20 \%$ \\
\hline & TaxCap & $0.08 \%$ & $0.92 \%$ & $0.34 \%$ & $-0.02 \%$ & $-0.09 \%$ & $-0.43 \%$ \\
\hline & $T a x C a p+R E S$ & $0.16 \%$ & $0.64 \%$ & $0.27 \%$ & $0.03 \%$ & $0.03 \%$ & $-0.02 \%$ \\
\hline & NoPolicy - pl & 8'672 & $5^{\prime} 871$ & 7’293 & $8^{\prime} 450$ & $9^{\prime} 529$ & $12^{\prime} 229$ \\
\hline & Cap - pl & $0.08 \%$ & $0.59 \%$ & $0.24 \%$ & $0.05 \%$ & $0.00 \%$ & $-0.27 \%$ \\
\hline \multirow[t]{9}{*}{ LUX } & NoPolicy & $32 ’ 582$ & $17^{\prime} 833$ & $24^{\prime} 567$ & $29 ’ 597$ & $37^{\prime} 762$ & 53'131 \\
\hline & Cap & $-0.46 \%$ & $-0.86 \%$ & $-0.59 \%$ & $-0.44 \%$ & $-0.33 \%$ & $-0.30 \%$ \\
\hline & $C a p+R E S$ & $-0.53 \%$ & $-1.05 \%$ & $-0.71 \%$ & $-0.52 \%$ & $-0.37 \%$ & $-0.32 \%$ \\
\hline & Invest & $-0.65 \%$ & $-1.27 \%$ & $-0.86 \%$ & $-0.63 \%$ & $-0.46 \%$ & $-0.39 \%$ \\
\hline & Invest $+R E S$ & $-0.63 \%$ & $-1.27 \%$ & $-0.86 \%$ & $-0.63 \%$ & $-0.44 \%$ & $-0.37 \%$ \\
\hline & TaxCap & $-0.45 \%$ & $-0.20 \%$ & $-0.44 \%$ & $-0.54 \%$ & $-0.52 \%$ & $-0.48 \%$ \\
\hline & $T a x C a p+R E S$ & $-0.53 \%$ & $-0.39 \%$ & $-0.56 \%$ & $-0.62 \%$ & $-0.56 \%$ & $-0.50 \%$ \\
\hline & NoPolicy - pl & $32^{\prime} 582$ & $17^{\prime} 831$ & $24 ’ 565$ & $29 ’ 596$ & $37^{\prime} 760$ & $53 ’ 139$ \\
\hline & Cap - pl & $-0.45 \%$ & $-0.85 \%$ & $-0.58 \%$ & $-0.43 \%$ & $-0.32 \%$ & $-0.33 \%$ \\
\hline
\end{tabular}


Table 12: Results for Malta, the Netherlands, Poland, Portugal, and Romania (annual consumption expenditure of different income quintiles in PPS)

\begin{tabular}{|c|c|c|c|c|c|c|c|}
\hline & & overall & q1 & $\mathrm{q} 2$ & q3 & $\mathrm{q} 4$ & $\mathrm{q} 5$ \\
\hline \multirow[t]{9}{*}{ MLT } & NoPolicy & $14^{\prime} 620$ & 10'722 & 12'649 & $14^{\prime} 855$ & 16 '069 & $18^{\prime} 819$ \\
\hline & Cap & $-2.06 \%$ & $-2.43 \%$ & $-2.16 \%$ & $-1.83 \%$ & $-1.80 \%$ & $-2.13 \%$ \\
\hline & $C a p+R E S$ & $-2.15 \%$ & $-2.94 \%$ & $-2.37 \%$ & $-1.86 \%$ & $-1.77 \%$ & $-1.96 \%$ \\
\hline & Invest & $-2.75 \%$ & $-3.87 \%$ & $-2.98 \%$ & $-2.31 \%$ & $-2.21 \%$ & $-2.56 \%$ \\
\hline & Invest $+R E S$ & $-2.46 \%$ & $-3.59 \%$ & $-2.74 \%$ & $-2.08 \%$ & $-1.96 \%$ & $-2.15 \%$ \\
\hline & TaxCap & $-2.05 \%$ & $2.03 \%$ & $-1.29 \%$ & $-2.86 \%$ & $-3.45 \%$ & $-3.86 \%$ \\
\hline & $T a x C a p+R E S$ & $-2.14 \%$ & $1.53 \%$ & $-1.50 \%$ & $-2.90 \%$ & $-3.43 \%$ & $-3.69 \%$ \\
\hline & NoPolicy - pl & $14^{\prime} 620$ & 10'722 & $12^{\prime} 648$ & $14^{\prime} 855$ & $16^{\prime} 069$ & $18^{\prime} 820$ \\
\hline & Cap - pl & $-2.07 \%$ & $-2.45 \%$ & $-2.17 \%$ & $-1.83 \%$ & $-1.80 \%$ & $-2.13 \%$ \\
\hline \multirow[t]{9}{*}{ NLD } & NoPolicy & $20^{\prime} 037$ & $16^{\prime} 606$ & $17^{\prime} 834$ & $19^{\prime} 576$ & $20 ’ 709$ & $25^{\prime} 403$ \\
\hline & Сар & $-0.57 \%$ & $-0.57 \%$ & $-0.61 \%$ & $-0.52 \%$ & $-0.52 \%$ & $-0.61 \%$ \\
\hline & $C a p+R E S$ & $-0.63 \%$ & $-0.80 \%$ & $-0.70 \%$ & $-0.56 \%$ & $-0.52 \%$ & $-0.57 \%$ \\
\hline & Invest & $-0.80 \%$ & $-1.04 \%$ & $-0.89 \%$ & $-0.69 \%$ & $-0.64 \%$ & $-0.72 \%$ \\
\hline & Invest $+R E S$ & $-0.76 \%$ & $-1.06 \%$ & $-0.86 \%$ & $-0.65 \%$ & $-0.58 \%$ & $-0.63 \%$ \\
\hline & ТахCap & $-0.57 \%$ & $-0.26 \%$ & $-0.56 \%$ & $-0.61 \%$ & $-0.67 \%$ & $-0.74 \%$ \\
\hline & $T a x C a p+R E S$ & $-0.63 \%$ & $-0.47 \%$ & $-0.65 \%$ & $-0.65 \%$ & $-0.67 \%$ & $-0.71 \%$ \\
\hline & NoPolicy - pl & $20^{\prime} 037$ & $16^{\prime} 604$ & $17^{\prime} 831$ & $19^{\prime} 575$ & $20 ’ 709$ & $25^{\prime} 411$ \\
\hline & Cap - pl & $-0.57 \%$ & $-0.52 \%$ & $-0.52 \%$ & $-0.50 \%$ & $-0.53 \%$ & $-0.76 \%$ \\
\hline \multirow[t]{9}{*}{ POL } & NoPolicy & $10^{\prime} 581$ & $7 ' 843$ & 9'196 & 9'792 & $11^{\prime} 043$ & $15^{\prime} 055$ \\
\hline & Сар & $-0.54 \%$ & $0.57 \%$ & $-0.17 \%$ & $-0.49 \%$ & $-0.69 \%$ & $-1.52 \%$ \\
\hline & $C a p+R E S$ & $-0.33 \%$ & $0.20 \%$ & $-0.14 \%$ & $-0.28 \%$ & $-0.39 \%$ & $-0.85 \%$ \\
\hline & Invest & $-2.00 \%$ & $-2.06 \%$ & $-1.82 \%$ & $-1.65 \%$ & $-1.84 \%$ & $-2.47 \%$ \\
\hline & Invest $+R E S$ & $-1.13 \%$ & $-1.23 \%$ & $-1.05 \%$ & $-0.92 \%$ & $-1.02 \%$ & $-1.37 \%$ \\
\hline & ТахCap & $-0.54 \%$ & $0.78 \%$ & $-0.12 \%$ & $-0.54 \%$ & $-0.76 \%$ & $-1.62 \%$ \\
\hline & $T a x C a p+R E S$ & $-0.34 \%$ & $0.41 \%$ & $-0.10 \%$ & $-0.33 \%$ & $-0.46 \%$ & $-0.94 \%$ \\
\hline & NoPolicy - pl & $10^{\prime} 581$ & 7'835 & 9'193 & $9^{\prime} 793$ & $11^{\prime} 045$ & $15^{\prime} 067$ \\
\hline & Cap - pl & $-0.54 \%$ & $0.74 \%$ & $-0.11 \%$ & $-0.51 \%$ & $-0.72 \%$ & $-1.65 \%$ \\
\hline \multirow[t]{9}{*}{ PRT } & NoPolicy & $13 ’ 589$ & 8'002 & $10^{\prime} 473$ & $12 ' 482$ & $14^{\prime} 575$ & $22^{\prime} 429$ \\
\hline & Cap & $-0.36 \%$ & $-0.41 \%$ & $-0.39 \%$ & $-0.35 \%$ & $-0.32 \%$ & $-0.35 \%$ \\
\hline & $C a p+R E S$ & $-0.36 \%$ & $-0.48 \%$ & $-0.47 \%$ & $-0.42 \%$ & $-0.32 \%$ & $-0.24 \%$ \\
\hline & Invest & $-0.76 \%$ & $-0.94 \%$ & $-0.94 \%$ & $-0.86 \%$ & $-0.69 \%$ & $-0.56 \%$ \\
\hline & Invest $+R E S$ & $-0.58 \%$ & $-0.76 \%$ & $-0.77 \%$ & $-0.70 \%$ & $-0.52 \%$ & $-0.36 \%$ \\
\hline & ТахСар & $-0.36 \%$ & $-0.11 \%$ & $-0.19 \%$ & $-0.24 \%$ & $-0.41 \%$ & $-0.60 \%$ \\
\hline & $T a x C a p+R E S$ & $-0.36 \%$ & $-0.18 \%$ & $-0.27 \%$ & $-0.31 \%$ & $-0.42 \%$ & $-0.49 \%$ \\
\hline & NoPolicy - pl & $13^{\prime} 589$ & $8^{\prime} 000$ & $10^{\prime} 471$ & $12^{\prime} 482$ & $14^{\prime} 576$ & $22^{\prime} 434$ \\
\hline & Cap - pl & $-0.36 \%$ & $-0.36 \%$ & $-0.36 \%$ & $-0.35 \%$ & $-0.33 \%$ & $-0.39 \%$ \\
\hline \multirow[t]{9}{*}{$\mathrm{ROU}$} & NoPolicy & $5 ’ 389$ & 3'262 & 4'394 & $5 ’ 186$ & $6^{\prime} 024$ & 8'091 \\
\hline & $C a p$ & $0.97 \%$ & $3.32 \%$ & $1.46 \%$ & $0.71 \%$ & $0.58 \%$ & $-0.06 \%$ \\
\hline & $C a p+R E S$ & $0.47 \%$ & $1.76 \%$ & $0.75 \%$ & $0.37 \%$ & $0.27 \%$ & $-0.13 \%$ \\
\hline & Invest & $-0.90 \%$ & $-0.65 \%$ & $-0.73 \%$ & $-0.74 \%$ & $-0.85 \%$ & $-1.29 \%$ \\
\hline & Invest $+R E S$ & $-0.55 \%$ & $-0.41 \%$ & $-0.46 \%$ & $-0.42 \%$ & $-0.51 \%$ & $-0.81 \%$ \\
\hline & ТахСар & $0.97 \%$ & $4.03 \%$ & $1.68 \%$ & $0.66 \%$ & $0.42 \%$ & $-0.42 \%$ \\
\hline & $T a x C a p+R E S$ & $0.48 \%$ & $2.44 \%$ & $0.96 \%$ & $0.32 \%$ & $0.12 \%$ & $-0.47 \%$ \\
\hline & NoPolicy - pl & 5,389 & $3^{\prime} 260$ & 4'392 & 5'186 & $6^{\prime} 025$ & 8'096 \\
\hline & Cap - pl & $0.97 \%$ & $3.30 \%$ & $1.45 \%$ & $0.71 \%$ & $0.58 \%$ & $-0.05 \%$ \\
\hline
\end{tabular}


Table 13: Results for Slovakia, Slovenia, Spain, Sweden, and the United Kingdom (annual consumption expenditure of different income quintiles in PPS)

\begin{tabular}{|c|c|c|c|c|c|c|c|}
\hline & & overall & q1 & q2 & q3 & q4 & q 5 \\
\hline \multirow[t]{9}{*}{ SVK } & NoPolicy & $8^{\prime} 322$ & 6'817 & 7’514 & $7^{\prime} 870$ & $8^{\prime} 529$ & $10 ' 889$ \\
\hline & Cap & $0.84 \%$ & $1.61 \%$ & $0.87 \%$ & $0.73 \%$ & $0.50 \%$ & $0.43 \%$ \\
\hline & $C a p+R E S$ & $0.52 \%$ & $0.91 \%$ & $0.52 \%$ & $0.45 \%$ & $0.33 \%$ & $0.38 \%$ \\
\hline & Invest & $-0.11 \%$ & $-0.22 \%$ & $-0.14 \%$ & $-0.12 \%$ & $-0.08 \%$ & $-0.01 \%$ \\
\hline & Invest $+R E S$ & $0.01 \%$ & $-0.09 \%$ & $-0.04 \%$ & $-0.02 \%$ & $0.02 \%$ & $0.14 \%$ \\
\hline & ТaxСap & $0.84 \%$ & $1.76 \%$ & $0.89 \%$ & $0.70 \%$ & $0.44 \%$ & $0.34 \%$ \\
\hline & TaxCap+RES & $0.52 \%$ & $1.06 \%$ & $0.53 \%$ & $0.42 \%$ & $0.27 \%$ & $0.30 \%$ \\
\hline & NoPolicy - pl & $8^{\prime} 322$ & $6^{\prime} 816$ & $7^{\prime} 514$ & $7^{\prime} 870$ & $8^{\prime} 529$ & $10 ' 891$ \\
\hline & Cap - pl & $0.84 \%$ & $1.56 \%$ & $0.87 \%$ & $0.73 \%$ & $0.52 \%$ & $0.47 \%$ \\
\hline \multirow[t]{9}{*}{ SVN } & NoPolicy & $15^{\prime} 288$ & $11^{\prime} 434$ & $14^{\prime} 203$ & $15^{\prime} 115$ & $15^{\prime} 979$ & $19^{\prime} 714$ \\
\hline & Cap & $-0.37 \%$ & $-0.40 \%$ & $-0.32 \%$ & $-0.38 \%$ & $-0.35 \%$ & $-0.42 \%$ \\
\hline & $C a p+R E S$ & $-0.41 \%$ & $-0.67 \%$ & $-0.30 \%$ & $-0.46 \%$ & $-0.29 \%$ & $-0.35 \%$ \\
\hline & Invest & $-0.87 \%$ & $-1.32 \%$ & $-0.74 \%$ & $-0.98 \%$ & $-0.63 \%$ & $-0.70 \%$ \\
\hline & Invest $+R E S$ & $-0.68 \%$ & $-1.17 \%$ & $-0.53 \%$ & $-0.79 \%$ & $-0.44 \%$ & $-0.50 \%$ \\
\hline & Тах Cap & $-0.37 \%$ & $0.27 \%$ & $-0.44 \%$ & $-0.23 \%$ & $-0.70 \%$ & $-0.73 \%$ \\
\hline & TaxCap+RES & $-0.41 \%$ & $0.02 \%$ & $-0.42 \%$ & $-0.32 \%$ & $-0.64 \%$ & $-0.66 \%$ \\
\hline & NoPolicy - pl & $15^{\prime} 288$ & $11^{\prime} 430$ & 14'195 & $15 ’ 112$ & $15^{\prime} 983$ & $19^{\prime} 729$ \\
\hline & Cap - pl & $-0.38 \%$ & $-0.40 \%$ & $-0.32 \%$ & $-0.37 \%$ & $-0.35 \%$ & $-0.42 \%$ \\
\hline \multirow[t]{9}{*}{ ESP } & NoPolicy & $17^{\prime} 878$ & 11'196 & $14 ’ 498$ & 17'204 & $19^{\prime} 845$ & $26 ' 659$ \\
\hline & Cap & $-0.20 \%$ & $-0.09 \%$ & $-0.14 \%$ & $-0.14 \%$ & $-0.17 \%$ & $-0.35 \%$ \\
\hline & $C a p+R E S$ & $-0.20 \%$ & $-0.34 \%$ & $-0.19 \%$ & $-0.17 \%$ & $-0.13 \%$ & $-0.21 \%$ \\
\hline & Invest & $-0.53 \%$ & $-0.89 \%$ & $-0.52 \%$ & $-0.44 \%$ & $-0.35 \%$ & $-0.57 \%$ \\
\hline & Invest $+R E S$ & $-0.38 \%$ & $-0.77 \%$ & $-0.40 \%$ & $-0.33 \%$ & $-0.24 \%$ & $-0.33 \%$ \\
\hline & ТaxCap & $-0.20 \%$ & $0.41 \%$ & $-0.09 \%$ & $-0.20 \%$ & $-0.33 \%$ & $-0.47 \%$ \\
\hline & TaxCap+RES & $-0.20 \%$ & $0.17 \%$ & $-0.14 \%$ & $-0.22 \%$ & $-0.30 \%$ & $-0.33 \%$ \\
\hline & NoPolicy - pl & $17^{\prime} 878$ & $11 ' 192$ & $14^{\prime} 494$ & $17 ’ 202$ & $19^{\prime} 844$ & $26^{\prime} 671$ \\
\hline & Cap - pl & $-0.20 \%$ & $-0.08 \%$ & $-0.13 \%$ & $-0.14 \%$ & $-0.17 \%$ & $-0.36 \%$ \\
\hline \multirow[t]{9}{*}{ SWE } & NoPolicy & $19^{\prime} 122$ & $13 ’ 564$ & $16 ' 251$ & $19^{\prime} 488$ & $21^{\prime} 213$ & $25^{\prime} 116$ \\
\hline & Cap & $-0.33 \%$ & $-0.55 \%$ & $-0.36 \%$ & $-0.29 \%$ & $-0.22 \%$ & $-0.28 \%$ \\
\hline & $C a p+R E S$ & $-0.50 \%$ & $-0.78 \%$ & $-0.55 \%$ & $-0.46 \%$ & $-0.37 \%$ & $-0.41 \%$ \\
\hline & Invest & $-0.44 \%$ & $-0.76 \%$ & $-0.49 \%$ & $-0.38 \%$ & $-0.27 \%$ & $-0.33 \%$ \\
\hline & Invest $+R E S$ & $-0.56 \%$ & $-0.89 \%$ & $-0.62 \%$ & $-0.51 \%$ & $-0.40 \%$ & $-0.44 \%$ \\
\hline & Тах Сap & $-0.33 \%$ & $-0.27 \%$ & $-0.28 \%$ & $-0.33 \%$ & $-0.38 \%$ & $-0.40 \%$ \\
\hline & TaxCap+RES & $-0.50 \%$ & $-0.50 \%$ & $-0.46 \%$ & $-0.51 \%$ & $-0.52 \%$ & $-0.52 \%$ \\
\hline & NoPolicy - pl & $19^{\prime} 122$ & $13 ’ 562$ & $16^{\prime} 249$ & $19^{\prime} 487$ & $21^{\prime} 214$ & $25^{\prime} 121$ \\
\hline & Cap - pl & $-0.33 \%$ & $-0.56 \%$ & $-0.38 \%$ & $-0.30 \%$ & $-0.22 \%$ & $-0.25 \%$ \\
\hline \multirow[t]{9}{*}{ GBR } & NoPolicy & $14^{\prime} 786$ & $10 ’ 677$ & $12^{\prime} 038$ & $13 ’ 712$ & $15^{\prime} 611$ & $21^{\prime} 903$ \\
\hline & Cap & $-0.09 \%$ & $-0.07 \%$ & $-0.10 \%$ & $-0.09 \%$ & $-0.06 \%$ & $-0.12 \%$ \\
\hline & $C a p+R E S$ & $-0.13 \%$ & $-0.15 \%$ & $-0.14 \%$ & $-0.12 \%$ & $-0.10 \%$ & $-0.14 \%$ \\
\hline & Invest & $-0.26 \%$ & $-0.39 \%$ & $-0.31 \%$ & $-0.24 \%$ & $-0.16 \%$ & $-0.21 \%$ \\
\hline & Invest $+R E S$ & $-0.22 \%$ & $-0.32 \%$ & $-0.25 \%$ & $-0.20 \%$ & $-0.16 \%$ & $-0.19 \%$ \\
\hline & ТахСар & $-0.09 \%$ & $0.09 \%$ & $-0.07 \%$ & $-0.11 \%$ & $-0.12 \%$ & $-0.19 \%$ \\
\hline & TaxCap+RES & $-0.13 \%$ & $0.03 \%$ & $-0.10 \%$ & $-0.14 \%$ & $-0.17 \%$ & $-0.21 \%$ \\
\hline & NoPolicy - pl & $14 ' 786$ & $10 ' 678$ & $12^{\prime} 038$ & $13^{\prime} 712$ & $15^{\prime} 611$ & $21^{\prime} 902$ \\
\hline & Cap $-\mathrm{pl}$ & $-0.09 \%$ & $0.04 \%$ & $-0.01 \%$ & $-0.05 \%$ & $-0.09 \%$ & $-0.26 \%$ \\
\hline
\end{tabular}


Table 14: ETS auction revenue in million EUR for scenario Cap with an emission cap and scenario Cap $+R E S$ with a cap and RES targets.

\begin{tabular}{|c|c|c|}
\hline & $\begin{array}{c}C a p \\
\text { (permit price: } \\
22.05 \text { EUR/tCO2) }\end{array}$ & $\begin{array}{c}C a p+R E S \\
\text { (permit price: } \\
12.18 \mathrm{EUR} / \mathrm{tCO} 2)\end{array}$ \\
\hline AUT & 313.8 & 170.9 \\
\hline BEL & 572.2 & 311.6 \\
\hline BGR & 683.0 & 372.0 \\
\hline HRV & 108.8 & 59.3 \\
\hline CYP & 60.0 & 32.7 \\
\hline CZE & 1054.5 & 574.3 \\
\hline DNK & 281.5 & 153.3 \\
\hline $\mathrm{EST}$ & 205.4 & 111.8 \\
\hline FIN & 376.1 & 204.8 \\
\hline FRA & 1234.4 & 672.3 \\
\hline DEU & 4515.5 & 2459.2 \\
\hline GRC & 782.2 & 426.0 \\
\hline HUN & 336.9 & 183.5 \\
\hline IRL & 212.3 & 115.6 \\
\hline ITA & 2173.6 & 1183.7 \\
\hline LVA & 46.1 & 25.1 \\
\hline LTU & 122.3 & 66.6 \\
\hline LUX & 39.2 & 21.4 \\
\hline MLT & 23.1 & 12.6 \\
\hline NLD & 756.8 & 412.2 \\
\hline POL & 2817.3 & 1534.3 \\
\hline PRT & 396.9 & 216.1 \\
\hline $\mathrm{ROU}$ & 1126.0 & 613.2 \\
\hline SVK & 346.1 & 188.5 \\
\hline SVN & 99.2 & 54.0 \\
\hline ESP & 1947.4 & 1060.6 \\
\hline SWE & 200.7 & 109.3 \\
\hline GBR & 2353.5 & 1281.8 \\
\hline
\end{tabular}

